\title{
O TAMANHO DA AMOSTRA PARA ESTUDO DOS CARACTERES PESO DE 50 GRÃOS, PESO DE ESPIGA E ALTURA DA PLANTA EM QUATRO GRUPOS DE CULTIVARES DE MILHO (Z $Z_{e a}$ mays L.)
}

JOSE FERNANDO SOARES DIAS

Engenheiro-Agrônomo

Orientador: Dr. Décio Barbin

Dissertação apresentada à Escola Superior de Agricultura "Luiz de Queiroz", da Universidade de São Paulo, para obtenção do título de Mestre em Experimentação e Estatística.

$P \mid R A C I C A B A$

Estado de São Paulo - Brasil

Agosto, 1978 
A Deus, pela vida

Aos meus pais José Raimundo e Léa, pelo bom exemplo e dedicação

Aos meus irmãos e parentes, peia união e cooperação

A Amariles, minha esposa, pelas alegrias e incentivos.

$D E D I C O$ 


\section{AGRADECIMENTOS}

Ao Professor Dr. Décio Barbin, pela sugestão do tema e, principalmente, pela valiosa orientação prestada na realização deste trabalho.

A Secretaria de Agricultura do Maranhão. Federação das Escolas Superiores do Maranhão e Empresa Maranhense de Pesquisa Agropecuária, pela oportunidade de aperfeiçoamento.

Ao Professor Dr. Cássio Roberto de Melo Godoi, pelos ensinamentos, sugestões e versão do resumo para o inglês.

Ao Dr. Ernesto Paterniani, pelo fornecimento dos dados de campo.

Ao Departamento de Matemática e Estatística da ESALQ. pelas ajudas concedidas.

Ao Professor Dr. Frederico Pimentel Gomes, pelos ensinamentos e revisão do original.

Aos demais Professores do Departamento de Matemática e Estatística da ESALQ, pelos ensinamentos e constante disponibilidade.

Aos cunhados Itaan e Vilma Santos da Fonseca, pelo apoio dispensado.

Aos colegas do curso de pös-graduação, pelo companheirismo e troca de idéias.

A Srta. Maria Izalina Ferreira Alves e família, pela amizade.

Aos funcionários do Departamento de Matemática e Estatística da ESALQ e à Srta. Fátima Pires de Araújo, pelo espírito de bem servir. 
Pág 。

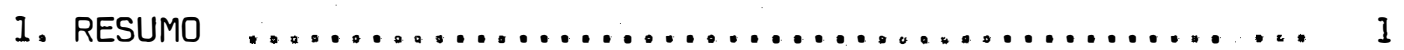

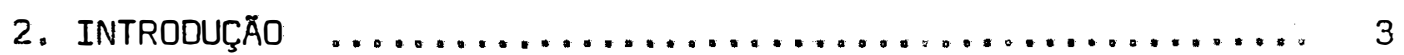

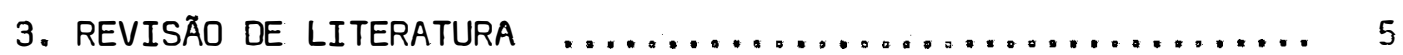

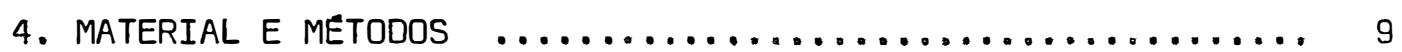

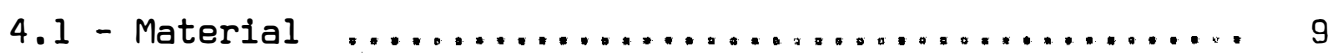

4.1.1 - Dados de campo ....................... 9

4.1 .2 - Dados simulados .......................... 10

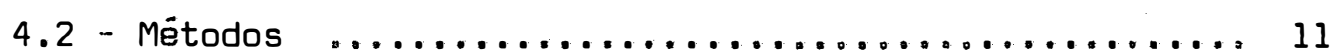

4.2.1 - Estudos preliminares .................. 11

4.2.1.1 - Modelo matemático $\ldots \ldots \ldots \ldots \ldots . .11$

4.2.1.2 - Sistema de equaçōes normais ..... 12

4.2.1.3 - Estimativas dos efeitos dos parâmetros $\ldots \ldots \ldots \ldots \ldots \ldots \ldots \ldots . . \ldots 14$

4.2.1.4 - Análise de variância ............ 15

4.2.1.5 - Componentes de variância ........ 17

4.2.1.6 - Estimativas dos componentes de variància .................... 18

4.2 .2 - Processo de simulação $\ldots \ldots \ldots \ldots \ldots \ldots \ldots, 18$

4.2.3 - Análise de variância dos dados simulados ... 24

4.2 .4 - Estudo de regressão ................... 25

4.2.4.1 - Modelo matemático ............ 25

4.2.4.2 - Estimativas dos parâmetros $e$ suas variâncias e covariâncias ....... 27 
Pág。

4.2.4.3 - Intervalos de confiança para o coe ficiente de variação ........ 29

4.2.4.4 - Anālise de variáncia e coeficiente de determinação $\ldots . . . . . . . .30$

4.2 .5 - Determinação do tamanho ótimo amostral ... 31

5. RESULTADOS $\ldots \ldots \ldots \ldots \ldots \ldots \ldots \ldots \ldots \ldots \ldots \ldots \ldots \ldots \ldots \ldots \ldots \ldots$

5.1 - Caräter Peso de 50 Grãos $\ldots \ldots \ldots \ldots \ldots \ldots \ldots \ldots \ldots \ldots$

5.1.1 - Análise de variáncia dos dados simulados .. 33

5.1 .2 - Anālise de variância dos coeficientes de variação e coeficiente de determinação ..... 36

5.1 .3 - Equações de regressão ............... 39

5.1 .4 - Estimativas do coeficiente de variação e res pectivos intervalos de confiança ....... 40

5.1.5 - Representação gráfica das equações de regres

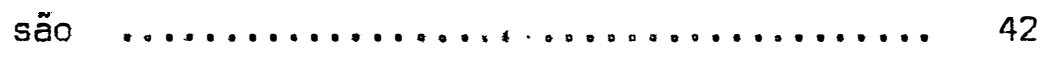

5.2 - Caräter Peso de Espiga ................... 45

5.2.1 - Análise de variância dos dados simulados .. 45

5.2.2 - Análise de variància dos coeficientes de variação e coeficiente de determinação ..... 48

5.2 .3 - Equações de regressão ............. 51

5.2.4 - Estimativas do coeficiente de variação e res pectivos intervalos de confiança ........ 51

5.2 .5 - Representação gráfica das equações de regres

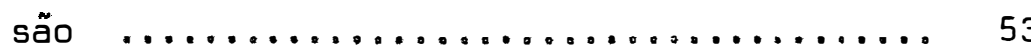


Pāg.

5.3 - Caráter Altura da Planta .................. 59

5.3.1 - Análise de variância dos dados simulados .. 59

5.3.2 - Análise de variância dos coeficientes de variação e coeficiente de determinação ..... 62

5.3 .3 - Equações de regressão $\ldots \ldots \ldots \ldots \ldots \ldots \ldots 6$

5.3 .4 - Estimativas do coeficiente de variação e res pectivos intervalos de confiança ....... 65

5.3.5 - Representação gráfica das equações de regres

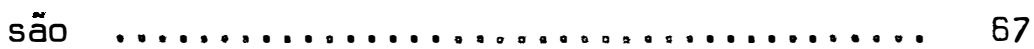

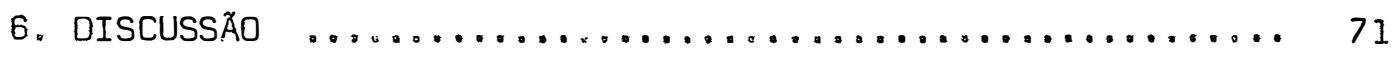

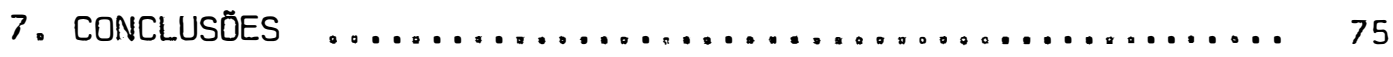

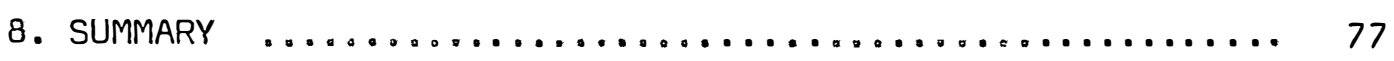

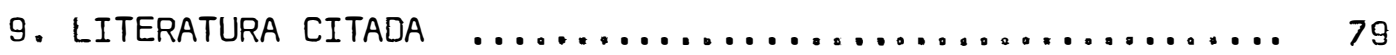




\section{RESUMO}

0 presente trabalho teve como objetivo principal determinar para os caracteres peso de 50 grăos, peso de espif̣a e altura da planta, o tamanho ótimo amostral para quatro grupos de cultivares de milho Chíbridos simples, híbridos duplos, variedades e

compostos). Determinou-se também, o tamanho ótimo da amostra para ca da caráter, no total dos quatro grupos de cultivares.

Visando-se a obter estimativas dos efeitos dos parâmetros e dos componentes de variância, utilizaram-se dados de dois experimentos, conduzidos em Piracicaba, SP, nos anos agrícolas 1972/ 173 e 1973/74. O delineamento experimental empregado foi o de blocos ao acaso com parcelas subdivididas ("split plot"). Para cada grupo foram utilizados dados de duas cultivares.

Utilizaram-se dados obtidos por simulação, através do computador eletrōnico IBM 1130. As unidades amostrais foram geradas, 
baseando-se no modelo matemático:

$$
x_{i j k \ell}=m+t_{i}+b_{j}+(t b)_{i j}+t_{k}^{\prime}+\left(t t^{\prime}\right)_{i k}+e_{i j k}+n_{i j k \ell} \cdot
$$

Os valores fixados para os parâmetros basearam-se nas estimativas ob tidas dos dois experimentos.

Foram escolhidos doze tamanhos amostrais, a saber: $5,10,15,20,25,30,35,40,45,50,55$ e 60 plantas por subparce la. Cada um desses tamanhos amostrais foi considerado em 100 análises de variância, para um determinado carāter e grupo de cultivares. Os dados simulados foram analisados por grupo de cul tivares, sendo calculada para cada análise de variância uma estimativa do coeficiente de variação, ao nível de planta. A essas estimativas, foi ajustada a equação $\bar{P}=\hat{A}+B X_{z}$ onde $X$ foi considerado o inverso do tamanho amostral.

Para cada caráter, de um modo geral, os valores mëdios das médias das cultivares variaram pouco com o tamanho amostral, porém mantiveram a mesma ordem de grandeza.

Baseando-se no método da curvatura máxima, os tamanhos amostrais foram de 13, 15 e 5 plantas por subparcela, pera os caracteres peso de 50 grãos, peso de espiga e altura da planta, res pectivamente.

0 tamanho amostral praticamente não variou dentro de cada caráter e sim dentro de cada grupo de cultivares. 


\section{INTRODUÇÃO}

0 grau de variabilidade fenotípica dos indivíduos es tá intimamente relacionado com o seu patrimônio genético e as condi ções ambientais onde se desenvolvem. Essa variabilidade, em grupos de cultivares, tem sido medida, em geral, pelos coeficlentes de variação.

E comumente aceito que a um aumento de diversidade de genótipos deve corresponder um acréscimo na variabilidade fenotípi ca. Entretanto, os trabalhos conduzidos, no assunto, ainda não deram margem à confirmação dessa hipótese, por motivos ignorados. Supõe-se que, tal fato, seja devido a problemas de Amostragem, interferindo dessa forma nas estimativas dos coeficientes de variação.

Existem vários estudos sobre o tamanho ótimo da parcela experimental, porém, sobre o tamanho da amostra para representar populações de milho, parece não haver muita bibliografia (SAN- 
CHEZ, 1972)。

Neste trabalho, foram estudados os seguintes caracte res: peso de 50 grãos, peso de espiga e altura da planta. Foram incluídos quatro grupos de cultivares de milho (2ea mays L.), representando quatro níveis de variabilidade genética: híbridos simples, híbridos duplos, variedades e compostas.

O objetivo principal do presente trabalho, foi deter minar, para cada caráter, o tamanho ótimo amostral para cada um dos grupos de cultivares. Determinou-se, também, o tamanho ótimo da amostra para cada caráter, no total dos quatro grupos de cultivares. 


\section{REVISÃO DE LITERATURA}

- bOX e MULLER (1958) apresentaram um método para simu lar variáveis normais, independentes, com médias zero e variâncias um, partindo de variáveis independentes e uniformemente distribuídas no intervalo $(0,1)$. O método é de fácil aplicação, mesmo em pe quenos computadores, evitando assim o uso de tabelas.

Para determinar intervalos de confiança para os pontos de máximo ou de mínimo de equações de regressão de segundo grau. D'AULISIO (1976) simulou 16.000 dados da variável aleatória $Y$, com distribuição aproximadamente normal de média zero e variância um.Os valores $Y_{i}$ foram obtidos partindo da variável aleatória $X$, uniformemente distribuída no intervalo $(0,1)$, e aplicando a transformação:

$$
Y=\frac{\sum_{i=1}^{k} x_{1}-\frac{k}{2}}{\sqrt{k / 12}},
$$


onde $k$ (nümero de valares $x_{i}$ ) foi considerado igual a 60 .

GODOI (1978) propôs um método para simular variáveis binormais, com médias e matriz de dispersão preestabelecidas, Partiu das variáveis aleatórias $X_{1}$ e $X_{2}$, independentes e uniformemente dis tribuídas no intervalo $(0,1)$ e, após as transformações sucessivas:

$$
\begin{aligned}
& \text { (a) }\left\{\begin{array}{l}
Y_{1}=2 \pi x_{1} \\
Y_{2}=\sqrt{-2 \ln X_{2}}
\end{array}\right. \\
& \text { (b) }\left\{\begin{array}{l}
Z_{1}=Y_{2} \cos Y_{1} \\
Z_{2}=Y_{2} \cos \left(\theta-Y_{1}\right),
\end{array}\right. \\
& \text { (c) }\left\{\begin{array}{l}
W_{1}=m_{1}+\sigma_{1} Z_{1} \\
W_{2}=m_{2}+\sigma_{2} Z_{2}
\end{array}\right.
\end{aligned}
$$

obteve a variāvel binormal $\left\{W_{1}, W_{2}\right\}$, com vetor de médias

$$
\left[\begin{array}{l}
m_{1} \\
m_{2}
\end{array}\right]
$$

e matriz de disfersão

$$
\left[\begin{array}{ccc}
\sigma_{1}^{2} & \rho & \sigma_{1} \sigma_{2} \\
\rho & \sigma_{1} \sigma_{2} & \\
\sigma_{2}^{2}
\end{array}\right]
$$

A maior parte dos pesquisadores tem usado o coeficiente de variaçăo para determinar o melhor tamanho e forma da parcela experimental. Os resultados mostraram que o coeficiente de varia ção decresceu com o aumento do tamanho da parcela (LANA et alii, 1953). 
0 método da curvatura máxima, assim chamado pela maneira como o tamanho da parcela é determinado, baseia-se no fato de que a variância e o coeficiente de variação decrescem com o aumento do tamanho da parcela (FEDERER, 1955).

Evans et alii (1961), citados por FERREIRA (1976), ba searam-se no método da curvatura máxima para determinar tamanhos ideais de parcelas para povoamento de vinte anos de idade e para caracteres, entre os quais: altura total, diāmetro à altura do peito e espessura da casca. Concluiram que uma amostra de vinte árvores seria ideal.

Para estabelecer a área ideal da parcela para inventários de eucaliptos, estabelecidos em regimes por alto fuste e taIhadia, FERREIRA (1976) baseou-se no método da curvatura máxima, utilizando os coeficientes de variação. Observou que, nos dois regimes considerados, a área ideal da parcela estava na faixa de 340 a $400 \mathrm{~m}^{2}$.

IMMER (1932), estudando o tamanho da amostra (nümero de beterrabas por parcela\} para determinar a percentagem de açücar; observou que erros padrões da média de 20 e $30 \%$, seriam obtidos facilmente, porém, o mesmo não ocorreria com um erro padrão de $10 \%$. Ve rificou que aumentando o número de repetições, o tamanho da amostra diminuia, porém, o decréscimo não foi uniforme, sendo mais acentuado ao passar de quatro para seis repetições.

FREY e RODGER (1961) estudaram os números mais eficientes de repetições e amostras por parcela, para determinar o nú- 
mero de espiguetas por espiga em aveia. Utilizaram dados de sete ex perimentos, onde foram tomadas quarenta e oito amostras (de uma espiga) por parcela. Observaram que para obter uma precisão da estima tiva da variāncia da média igual a $8 \%$ da estimativa da média, devem ser usadas sete repetições e seis amostras por parcela.

Para determinar os prejuizos para os frutos da macieira, LeRoux (1961) realizou, em dois anos, oito amostragens durante o período de produção. Observou que, para obter erros padrões da média de 10 e 20\%, o número de plantas variou de 140 a 255 e 35 a 65, respectivamente. Para os dois casos, o número de galhos por planta, a ser examinado, variou de 50 a 100.

SANCHEZ (1972), para determinar o tamanho ótimo da amostra (número de plantas por parcela), para representar populaçōes de milho, utilizou dados de um experimento com seis populações. Ado tou quatro tamanhos amostrais: 8, 16, 24 e 32 plantas por parcela. Baseando-se no método da curvatura máxima, observou que, para quatro repetições, o tamanho ätimo foi de oito plantas pcr parcela. En tretanto, para obter estimativas com níveis de precisão mais aceitá veis, sugere que sejam usadas dezessete plantas por parcela e seis ropetições. 
9.

4. MATERIAL E METODOS

\section{1 - Material}

\subsection{1 - Dados de campo}

Para o presente estudo, utilizaram-se dados que foram gentilmente cedidos pelo Dr. Ernesto Paterniani, Chefe do Depar tamento de Genética e Diretor do Instituto de Genética da Escola Su perior de Agricultura "Luiz de Queiroz" (ESALQ), Piracicaba, SP. Es ses dados são oriundos de experimentos conduzidos, em Piracicaba, ros anos agricolas de 1972/73 e 1973/74. O delineamento experimental em pregado foi o de blocos ao acaso, com parcelas subdivididas ("split plot") e com dez repetições. Cada parcela foi constituída por dez fileiras, de dez metros de comprimento, espaçadas entre si de um me tro. Nas parcelas foram estudadas dez cultivares de milho, a saber: Húbridos Simples (IP-1227 F, IAC-6904 F, M 206 e D G); Híbridos Du 
plos (HMD 6999 B e AG 257); Variedades (Centralmex e Maya X): Compostos (Dentado e Flint). Nas subparcelas foram estudadas duas densidades de plantio: 33.333 e 50.000 plantas por hectare, que corres pondem a uma planta a cada $30 \mathrm{~cm}$ e a cada $20 \mathrm{~cm}$, respectivamente. No semeio foram usadas duas sementes por cova, sendo mantida uma plan ta por cova, após o desbaste. Foram dispensados os tratos culturais: usuais para a cultura do milho. Para as anotações dos caracteres es tudados, foram tomadas plantas competitivas, ao acaso. das três fileiras centrais, em número de dez plantas dos híbridos simples, vin te dos híbridos duplos e quarenta das variedades e compostos.

$$
\text { Visando-se a uniformizar o número de cultivares por }
$$

grupo, foram eliminados, ao acaso, os dados dos Híbridos Simples (M 206 e $D G]$.

Os dados utilizados, neste trabalho, são referentes aos seguintes caracteres: peso de 50 grãos, peso de espiga (sem paIha) e altura da planta.

Os dados do caráter altura da planta são provenientes apenas do ensaio do ano agrícola 1973/74, uma vez que no ano agrícola $1972 / 73$ não foram efetuadas anotações para esse caráter.

\subsection{2 - Dados simulados}

Neste trabalho, foram utilizados 18.720.000 dados, obtidos por simulação, através do computador eletrónico IBM 1130 do Departamento de Matemätica e Estatística da ESALQ. 


\section{2 - Métodos}

\subsection{1 - Estudos preliminares}

Os estudos preliminares foram aplicados: aos dados de campo, visando principalmente obter estimativas dos efeitos dos parámetros em estudo e dos componentes de variáncia, referentes ao mo delo matemätico considerado.

\subsubsection{1 - Modelo matemätico}

0 modelo matemático, adaptado de PIMENTEL GOMES(1976) e KEMPTHORNE (1965), considerado para o experimento em parcelas sub divididas, com as parcelas dispostas em blocos ao acaso e com L uni dades amostrais por subparcela, foi:

$$
x_{i j k \ell}=m+t_{i}+b_{j}+(t b)_{i j}+t_{k}^{\prime}+\left(t t^{\prime}\right)_{i k}+e_{i j k}+n_{i j k \ell} .
$$

onde: $x_{i j k \ell}=$ valor da $\ell$-ésima unidade amostral da ik-ésima subparcela, no j-ésimo bloco;

$m$ = média geral, teörica:

$t_{i}=$ efeito do i-ësimo tratamento $T_{\text {: }}$

$b_{j}=$ efeito do j-ésimo bloco;

(tb) $_{i j}=$ efeito da interação do $i$-ésimo tratamento $T$ com o j-ési mo bloco ou efeito residual das parcelas, onde se supõe (tb) ${ }_{i j} \cap N\left(0, \sigma_{t b}^{2}\right)$;

$t_{k}^{\prime}=$ efeito do $k$-ésimo tratamento $T^{\prime}$ : 


$$
\begin{aligned}
\text { (tt' }_{i k}= & \text { efeito da interação do } i \text {-ésimo tratamento } T \text { com o k-ési } \\
& \text { mo tratamento } T^{\prime} ; \\
e_{i j k}= & \text { efeito da ik-ésima subparcela,no j-ésimo bloco ou er- } \\
& \text { ro experimental, onde se supõe } e_{i j k} \cap N\left(0, \sigma_{e}^{2}\right) ; \\
n_{i j k \ell}= & \text { efeito associado à } \ell \text {-ésima unidade amostral da ik-ési- } \\
& \text { ma subparcela, no } j \text {-ésimo bloco ou erro amostral, onde } \\
& \text { se supõe } n_{i j k \ell} \cap N\left(0, \sigma_{n}^{2}\right) . \\
i= & 1,2: j=1,2, \ldots, 10 ; k=1,2: \ell=1,2, \ldots, L .
\end{aligned}
$$

A notação $X \cap N\left(m, \sigma^{2}\right)$, anteriormente usada, significa que a variável aleatória $X$ tem distribuição normal com média m e variância $\sigma^{2}$.

\subsubsection{2 - Sistema de equações normais \\ O sistema de equações normais, obtido através do më-} todo dos quadrados mínimos, foi: 
$I J K L \hat{m}+J K L \sum_{i} E_{i}+I K L \sum_{j} G_{j}+K L \sum_{i j}(t b)_{i j}+I J L \sum_{k} E_{k}^{\prime}+$

$+J L \sum_{i k}\left(t t^{\prime}\right)_{i k}+L \sum_{i j k} \hat{e}_{i j k}=x_{0 . .}=G$

$J K L \dot{m}+J K L E_{i}+K L \sum_{j} G_{j}+K L \sum_{j}(t b)_{i j}+J L \sum_{k} E_{k}^{\prime}+$

$+J L \sum_{k}^{\sum}\left(t t^{\prime}\right)_{i k}+L \sum_{j k} \hat{e}_{i j k}=x_{i} \ldots=T_{i}$

$I K L \hat{m}+K L \sum_{i} E_{i}+I K L G_{j}+K L \sum_{i}(t b)_{i j}+I L \sum_{k} t_{k}^{\prime}+$

$+L \sum_{i k}\left(t t^{\prime}\right)_{i k}+L \underset{i k}{\Sigma_{1}} \hat{e}_{i j k}=x_{j_{j}}{ }^{\circ}=B_{j}$

$K L \hat{m}+K L E_{i}+K L G_{j}+K L(t b)_{i j}+L \sum_{k} E_{k}^{\prime}+$

$+L \sum_{k}(t)_{i k}+L \sum_{k} \hat{e}_{i j k}=x_{i j \ldots}=P_{i j}$

$I J L \hat{m}+J L \sum_{i} E_{i}+I L \sum_{j} G_{j}+L \sum_{i j}(t b)_{i j}+I J L E_{k}^{\prime}+$

$+J L \sum_{i}\left(t t^{\prime}\right)_{i k}+L \sum_{i j} \hat{e}_{i j k}=x_{0}{ }^{\circ} k^{\prime}=T_{k}^{\prime}$

$J L \tilde{m}+J L E_{i}+L \sum_{j} G_{j}+L \sum_{j}(t b)_{i j}+J L E_{k}^{\prime}+$

$+J L\left(t^{\prime}\right)_{i k}+L \sum_{j} \hat{e}_{i j k}=x_{i \cdot k^{\prime}}=P_{i k}$

$L \hat{m}+L E_{i}+L G_{j}+L(t b)_{i j}+L E_{k}^{\prime}+$

$+L\left(t t^{\prime}\right)_{i k}+L \hat{e}_{i j k}=x_{i j k}=P_{i j k}$

onde: $G=$ total geral:

$T_{i}=$ total do $i$-ésimo tratamento $T$ \&

$B_{j}=$ total do j-ésimo bloco: 


$$
\begin{aligned}
P_{i j}= & \text { total da parcela que recebeu o } i \text {-ésimo tratamento } T \text {, no } \\
& j \text {-ésimo bloco: } \\
T_{k}^{\prime}= & \text { total do } k \text {-ésimo tratamento } T^{\prime}: \\
P_{i k}= & \text { total das subparcelas que receberam o } i \text {-ésimo e o k-ésimo } \\
& \text { tratamento } T \& T^{\prime} \text {, respectivamente: } \\
P_{i j k}= & \text { total da } i k \text {-ésima subparcela, no j-ésimo bloco. }
\end{aligned}
$$

\subsubsection{3 - Estimativas dos efeitos dos parâmetros}

Partindo-se do sistema de equações normais e introduzindo-se as restrições:
$\sum t_{i}=0$
$\sum_{j} G_{j}=0$
$\sum_{k} \epsilon_{k}^{\prime}=0$
$\sum_{i}(t b)_{i j}=0$
$\sum_{j}^{(t b)_{i j}}=0$
$\sum_{i j}(t b)_{i j}=0:$
$\sum_{i}\left(t t^{\prime}\right)_{i k}=0$
$\sum_{k}\left(t^{\prime} t^{\prime}\right)_{i k}=0 ?$
$\sum_{i k}\left(t t^{\prime}\right)_{i k}=0$

$$
\sum_{j} \hat{e}_{i j k}=0
$$$$
\sum_{k} \hat{e}_{i j k}=0
$$$$
\sum_{i j} \hat{e}_{i j k}=0 \text { : }
$$$$
\sum_{i k} \hat{\mathrm{e}}_{i j k}=0
$$
$\sum_{j k} \hat{e}_{i j k}=0$
$\sum_{i j k} \hat{e}_{i j k}=0$,

obtiveram-se:

$$
\begin{aligned}
\tilde{m} & =\frac{G}{I J K L} ; \\
E_{i} & =\frac{T}{J K L}-\tilde{m} ; \\
G_{j} & =\frac{B_{j}}{I K L}-\hat{m} ;
\end{aligned}
$$




$$
\begin{aligned}
(t B)_{i j} & =\frac{P_{i j}}{K L}-\hat{m}-\hat{t}_{i} \cdot G_{j}: \\
t_{k}^{\prime} & =\frac{T_{k}^{\prime}}{I J L}-\hat{m} . \\
\left(t t^{\prime}\right)_{i k} & =\frac{P_{i k}}{J L}-\hat{m}-E_{i}-E_{k}^{\prime}: \\
\hat{e}_{i j k} & =\frac{P_{i j k}}{L}-\hat{m}-E_{i}-G_{j}-(t B)_{i j}-E_{k}^{\prime}-\left(t t^{\prime}\right)_{i k} .
\end{aligned}
$$

\subsubsection{4 - Anālise de variância}

Para cada ano agrícola e para cada caráter, as análises de variância foram feitas por grupo de cultivares.

Preliminarmente, os dados referentes aos caracteres peso de 50 grãos e peso de espiga foram corrigidos para a umidade de $15: 5 \%$, empregando-se a förmula:

$$
P_{15,5 \%}=\frac{P C(1-U)}{0,845},
$$

onde: $P_{15,5 \%}=$ peso de campo corrigido para a umidade de $15,5 \%$ :

$P C=$ peso de campo observado:

$U=$ umidade de campo observada.

O esquema da anälise de variāncia, de acordo com KOCH e RIGNEY (1951), encontra-se na Tabela 1. 
Tabela 1 - Esquema da análise de variância, para cada ano agrícola e para cada caráter, feita por grupo de cultivares.

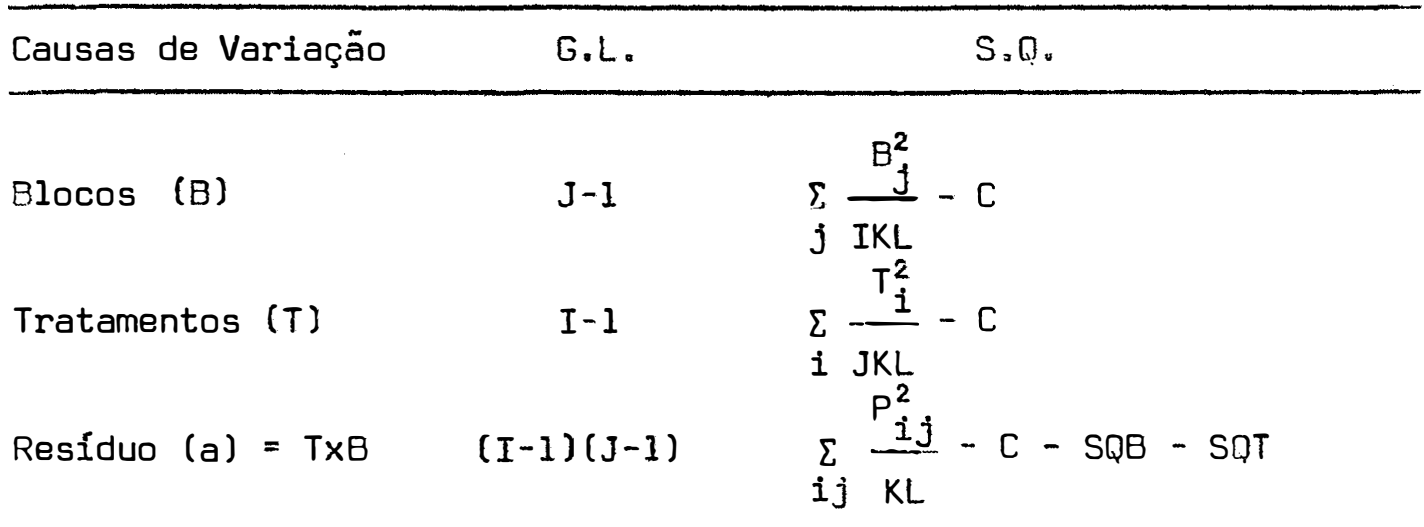

(Parcelas)

Tratamentos $\left(T^{\circ}\right)$

Interação $\mathrm{TxT}^{\text {* }}$

Resíduo (b)
$(I J-1)$

$$
k-1
$$$$
\sum_{k} \frac{\left(T_{k}^{\prime}\right)^{2}}{I^{2} L}-C
$$

$(I-1)(K-1)$

$P^{2}$
(Subparcelas)

Erro amostral

To t a I

IJKL-I
(IJK-1)

$\operatorname{IJK}(L-1)$ por subtração

onde: $C=\frac{G^{2}}{I J K L}$. 


\subsubsection{5 - Componentes de variância}

Os componentes de variância foram obtidos a partir das fórmulas das somas de quadrados (Tabela 1), e admitindo-se o mo delo matemático (1) do Tipo Misto, onde foram considerados aleató. rios (tb) ${ }_{i j}, e_{i j k}$ e $n_{i j k \ell}$. Esses componentes podem ser visualizados na Tabela 2.

Tabela 2 - Componentes de variância, considerando-se o modelo matemätico do Tipo Misto.

\begin{tabular}{|c|c|c|}
\hline Causas de Variagão & Q.M. & $E\left(Q \cdot M_{0}\right)$ \\
\hline Blocos $(B)$ & $\mathrm{V}_{1}$ & $\sigma_{n}^{2}+L \sigma_{e}^{2}+K L \sigma_{t b}^{2}+\theta_{1}$ \\
\hline Tratamentos (T) & $v_{2}$ & $\sigma_{n}^{2}+L \sigma_{e}^{2}+K L \sigma_{t b}^{2}+\theta_{2}$ \\
\hline Resíduo $(a)=T \times B$ & $v_{3}$ & $\sigma_{n}^{2}+L \sigma_{e}^{2}+K L \sigma_{t b}^{2}$ \\
\hline Tratamentos $\left(T^{\prime}\right)$ & $V_{4}$ & $\sigma_{n}^{2}+L \sigma_{e}^{2}+\theta_{3}$ \\
\hline Interação $T \times T^{\prime}$ & $v_{5}$ & $\sigma_{n}^{2}+L \sigma_{e}^{2}+\theta_{4}$ \\
\hline Resíduo (b) & $v_{6}$ & $\sigma_{n}^{2}+L \sigma_{e}^{2}$ \\
\hline Erro amostral & $v_{7}$ & $\sigma_{n}^{2}$ \\
\hline
\end{tabular}

onde: $\theta_{1}=\frac{I K L}{J-1} \sum_{j} b_{j}^{2} ; \quad \theta_{3}=\frac{I J L}{K-1} \sum_{k}\left(t_{k}^{\prime}\right)^{2}:$

$$
\theta_{2}=\frac{J K L}{I-1} \sum_{i} t_{i}^{2}: \quad \epsilon_{4}=\frac{J L}{(I-1)(K-1)} \sum_{i k}\left(t t^{\prime}\right)_{i k}^{2} .
$$




\subsubsection{6 - Estimativas dos componentes de variância} As estimativas dos componentes de variância foram ob

tidas por:

$$
\begin{aligned}
\hat{\sigma}_{n}^{2} & =v_{7} \\
\hat{\sigma}_{n}^{2}+L \hat{\sigma}_{e}^{2} & =v_{6} \Longrightarrow \hat{\sigma}_{e}^{2}=\frac{V_{6}-V_{7}}{L} \\
\hat{\sigma}_{n}^{2}+L \hat{\sigma}_{e}^{2}+K L \tilde{\sigma}_{t b}^{2} & =v_{3} \Longrightarrow \hat{\sigma}_{t b}^{2}=\frac{V_{3}-V_{6}}{K L}
\end{aligned}
$$

\subsection{2 - Erocesso de simulação}

No processo de simulação, as unidades amostrais foram geradas baseadas no modelo matemático (1). Foi usada a subrotina UNNOR, que simula variăveis aleatórias, independentes, com distribuição normal de média m e variância $\sigma^{2}$. A subrotina UNNOR baseia-se no trabalho de BOX e MULLER (1958). cujo fundamento matemätico è o seguinte.

Sejam $U_{1}$ e $U_{2}$ duas variáveis aleatórias, independentes, com distribuição uniforme no intervalo $(0,1)$. A função de densidade conjunta dessas variáveis aleatórias é:

$$
\begin{aligned}
& g\left(u_{1}, u_{2}\right)=1, \quad \text { para } 0<u_{i}<1 \\
& g\left(u_{1}, u_{2}\right)=0, \text { para } u_{i} \notin[0,1]
\end{aligned}
$$

Sejam as variáveis aleatórias $X_{1}$ e $X_{2}$, definidas por:

$$
x_{1}=\left(-2 \ln U_{1}\right)^{1 / 2} \cos 2 \pi U_{2}
$$




$$
x_{2}=\left(-2 \ln U_{1}\right)^{1 / 2} \operatorname{sen} 2 \pi u_{2} .
$$

As inversas das relações (2) e (3) são:

$$
\begin{aligned}
& U_{1}=e^{-\left(x_{1}^{2}+x_{2}^{2}\right) / 2} \\
& U_{2}=\frac{1}{2 \pi} \operatorname{arctg} \frac{x_{2}}{x_{1}} .
\end{aligned}
$$

O Jacobiano da transformação é:

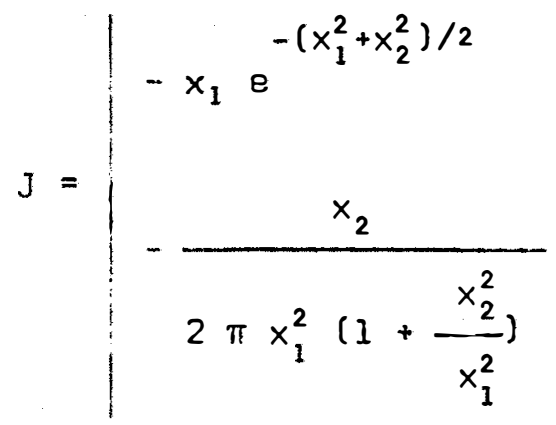

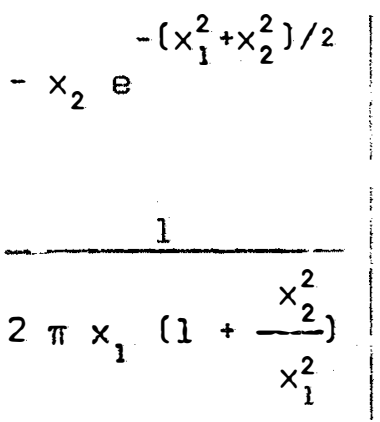

Desenvolvendo-se o Jacobiano, obtëm-se, em valor ab-

soluto:

$$
|J|=\frac{1}{2 \pi} e^{-\left(x_{1}^{2}+x_{2}^{2}\right) / 2}
$$

A função de densidade conjunta, das variäveis aleató rias $x_{1}$ e $x_{2}, \vec{e}:$

$$
f\left(x_{1}, x_{2}\right)=g\left(u_{1}, u_{2}\right) \quad|J|
$$

Substituindo-se em (5) o valor do $|\mathrm{J}|$, obtido em (4). tem-se:

$$
f\left(x_{1}, x_{2}\right)=\frac{1}{2 \pi} e^{-\left(x_{1}^{2}+x_{2}^{2}\right) / 2} \text {, para } \underbrace{-\infty<x_{1}<\infty}_{-\infty<x_{2}<\infty}
$$


Como a função de densidade conjunta $f\left(x_{1}, x_{2}\right)$ pode ser partida em $f_{1}\left(x_{1}\right)$ e $f_{2}\left(x_{2}\right)$ :

$$
\begin{aligned}
f\left(x_{1}, x_{2}\right) & =\frac{1}{2 \pi} e^{-\left(x_{1}^{2}+x_{2}^{2}\right) / 2} \\
& =\frac{1}{\sqrt{2 \pi}} e^{-\left(x_{1}^{2}\right) / 2} \frac{1}{\sqrt{2 \pi}} e^{-\left(x_{2}^{2}\right) / 2} \\
& =f_{1}\left(x_{1}\right) \cdot f_{2}\left(x_{2}\right),
\end{aligned}
$$

as variáveis aleatórias $x_{1}$ e $x_{2}$ são independentes.

Comparando-se as funções de densidade $f_{1}\left(x_{1}\right)$ e $f_{2}\left(x_{2}\right)$ com a função de densidade da distribuição normal de uma variável, ob serva-se que?

$$
x_{1} \cap N(0,1) \quad \text { e } \quad x_{2} \cap N(0,1)
$$

Os valores fixados para os parâmetros dos quatro grupos de cultivares, foram baseados nas estimativas obtidas das anālises de variância $(4.2 .1 .4)$ e são apresentados, por caráter, nas seguintes Tabelas: peso de 50 grãos (Tabela 3), peso de espiga (Tabela 4) e altura da planta (Tabela 5)。 
Tabela 3 - Caráter peso de 50 grãos $(g)$. Valores fixados para os pará metros, correspondentes aos quetro grupos de cultivares.

\begin{tabular}{|c|c|c|c|c|}
\hline Parāmetros & $\begin{array}{c}\text { HIbridos } \\
\text { Simples }\end{array}$ & $\begin{array}{c}\text { HIbridos } \\
\text { Duplos }\end{array}$ & Variedades & Compostos \\
\hline$m$ & 12,00 & 13,00 & 14,00 & 15,00 \\
\hline$t_{1}$ & $-0,40$ & $-0,05$ & 0,15 & 0,30 \\
\hline$t_{2}$ & 0,40 & 0,05 & $-0,15$ & $-0,30$ \\
\hline$b_{1}$ & 0,25 & $-1,00$ & $-0,80$ & $-0,50$ \\
\hline$b_{2}$ & $-0,80$ & 1,10 & $-0,30$ & 0,30 \\
\hline$b_{3}$ & 0,25 & 1,70 & 0,60 & 0,50 \\
\hline$b_{4}$ & $-0,05$ & -0.20 & 0,40 & $-0,40$ \\
\hline$b_{5}$ & 0,40 & 0,80 & 0,90 & $-0,60$ \\
\hline$b_{6}$ & 0.25 & $-1,20$ & 0,80 & $-0,10$ \\
\hline$b_{7}$ & 0,80 & 0,90 & 0,20 & 0,60 \\
\hline$b_{8}$ & 0,30 & $-2,30$ & 0,10 & $-0,80$ \\
\hline$b_{9}$ & $-0,55$ & $-1,10$ & $-1,50$ & $-0,30$ \\
\hline$b_{10}$ & $-0,85$ & 1,30 & $-0,40$ & 1,30 \\
\hline$\sigma_{t b}^{2}$ & 0,25 & 0,09 & 080 & 0,04 \\
\hline$t_{i}^{\prime}$ & 0,70 & 0,75 & 0,25 & 0,25 \\
\hline$t_{2}^{5}$ & $-0,70$ & $-0,75$ & $-0,25$ & $-0,25$ \\
\hline$\left(t t^{\prime}\right)_{11}$ & $-0,30$ & 0,05 & $-0,30$ & $-0,30$ \\
\hline$\left(t t^{\prime}\right)_{12}$ & 0,30 & $-0,05$ & 0,30 & 0,30 \\
\hline$\left(t t^{0}\right)_{21}$ & 0,30 & $-0,05$ & 0,30 & 0,30 \\
\hline$\left(t t^{\prime}\right)_{22}$ & $-0,30$ & 0,05 & $-0,30$ & $-0,30$ \\
\hline$\sigma_{e}^{2}$ & 1,00 & 0,50 & 0,50 & 1,00 \\
\hline$\sigma_{n}^{2}$ & 7,30 & 7,80 & 9,00 & 8,40 \\
\hline
\end{tabular}


Tabela 4 - Caräter peso de espiga $(g)$. Valores fixados para os parâ metros, correspondentes aos quatro grupos de cultivares.

\begin{tabular}{|c|c|c|c|c|}
\hline Parâmetros & $\begin{array}{l}\text { Híbridos } \\
\text { Simples }\end{array}$ & $\begin{array}{c}\text { HIbridos } \\
\text { Duplos }\end{array}$ & Variedades & Compostos \\
\hline$m$ & 114,00 & 135,00 & 140.00 & 138,00 \\
\hline$t_{1}$ & $-4,50$ & 4,80 & $-2,50$ & 7,80 \\
\hline$t_{2}$ & 4,50 & $-4,80$ & 2,50 & $-7,80$ \\
\hline$b_{1}$ & 2,20 & 14,30 & $-29,90$ & $-13,20$ \\
\hline$b_{2}$ & $-12,25$ & $-3,10$ & $-9,60$ & -9.30 \\
\hline$b_{3}$ & 6,15 & 11,80 & -19.50 & 6,50 \\
\hline$b_{4}$ & $-1,25$ & $-11,80$ & 5,00 & $-19,40$ \\
\hline$b_{5}$ & $-7,10$ & $-9,60$ & 17,30 & 4,50 \\
\hline$b_{6}$ & 4,80 & 10,60 & 13,70 & $-5,80$ \\
\hline$b_{7}$ & $-9,10$ & 1,10 & 1,40 & 18,10 \\
\hline$b_{8}$ & 6,85 & $-0,05$ & 13,30 & 11,20 \\
\hline$b_{9}$ & 19,55 & $-5,90$ & $-12,40$ & $-2,60$ \\
\hline$b_{10}$ & $-9,85$ & $-7,35$ & 20,70 & 10,00 \\
\hline$\sigma_{t b}^{2}$ & 20,00 & 13,00 & 5,00 & 10,00 \\
\hline$t_{1}^{y}$ & 10,80 & 18,50 & 19,00 & 15,80 \\
\hline$t_{2}^{\prime}$ & $-10,80$ & $-18,50$ & $-19,00$ & $-15,80$ \\
\hline$\left(t t^{\prime}\right)_{11}$ & -0.15 & 0,50 & $-5,40$ & $-0,70$ \\
\hline$\left(t t^{\prime}\right)_{12}$ & 0,15 & $-0,50$ & 5,40 & 0,70 \\
\hline$\left(t t^{\prime}\right)_{21}$ & 0.15 & $-0,50$ & 5,40 & 0,70 \\
\hline$\left(t t^{\prime}\right)_{22}$ & $-0,15$ & 0,50 & $-5: 40$ & $-0,70$ \\
\hline$\sigma_{\mathrm{e}}^{2}$ & 12,00 & 12,00 & 20,00 & 6,00 \\
\hline$\sigma_{n}^{2}$ & 38,00 & 46,00 & 48,00 & 45,00 \\
\hline
\end{tabular}


Tabela 5 - Caráter altura da planta $(\mathrm{cm})$. Valores fixados para os parâ metros, correspondentes aos quatro grupos de cultivares.

\begin{tabular}{|c|c|c|c|c|}
\hline Parâmetros & $\begin{array}{l}\text { Híbridos } \\
\text { Simples }\end{array}$ & $\begin{array}{l}\text { Híbridos } \\
\text { Duplos }\end{array}$ & Variedades & Compostos \\
\hline $\mathrm{m}$ & 275,00 & 297,00 & 325,00 & 312,00 \\
\hline$t_{1}$ & $-0,80$ & 2,50 & $-0,20$ & 6,30 \\
\hline$t_{2}$ & 0,80 & $-2,50$ & 0,20 & $-6,30$ \\
\hline$b_{1}$ & 4,70 & $-7,70$ & 4,20 & 12,30 \\
\hline$b_{2}$ & 8,70 & 13,60 & 1,80 & 7,80 \\
\hline$b_{3}$ & 4,20 & 9,30 & $-3,30$ & $-8,50$ \\
\hline$b_{4}$ & $-16,30$ & $-11,00$ & $-14,80$ & $-10,00$ \\
\hline$b_{5}$ & 13,70 & 3,00 & 5,70 & $-2,80$ \\
\hline$b_{6}$ & 11,20 & 5,60 & $-1,50$ & $-14,80$ \\
\hline$b_{7}$ & $-10,80$ & $-10,90$ & $-7,30$ & $-4,30$ \\
\hline$b_{8}$ & $-1,40$ & $-2,00$ & $C_{0} 80$ & $-0,30$ \\
\hline$b_{9}$ & $-11,60$ & $-0,50$ & 6.20 & 9,80 \\
\hline$b_{10}$ & $-2,40$ & 0,60 & 8,20 & 10,80 \\
\hline$\sigma_{t b}^{2}$ & 5,00 & 5,00 & 13,00 & 9,00 \\
\hline$t_{i}^{\prime}$ & $-0,60$ & $-1,70$ & $-3,00$ & $-0,70$ \\
\hline$t_{2}^{\prime}$ & 0,60 & 1,70 & 3,00 & 0,70 \\
\hline$\left(t t^{\prime}\right)_{11}$ & 1,00 & $-0,80$ & 4,70 & 0,50 \\
\hline$\left(t t^{\prime}\right)_{12}$ & $-1,00$ & 0,80 & $-4,70$ & $-0,50$ \\
\hline$\left(t t^{\prime}\right)_{21}$ & $-1,00$ & 0.80 & -4.70 & $-0,50$ \\
\hline$\left(t t^{\prime}\right)_{22}$ & $1 ; 00$ & $-0,80$ & 4,70 & 0,50 \\
\hline$\sigma_{e}^{2}$ & 17,00 & 12,00 & 5,00 & 6,00 \\
\hline$\sigma_{n}^{2}$ & 22,00 & 19,00 & 24,00 & 24,00 \\
\hline
\end{tabular}




\subsection{3 - Anälise de variância dos dados simulados}

Para cada caráter estudado, as análises de variância foram feitas por grupo de cultivares. Foram realizadas 14.400 análises de variância, sendo 4.800 para cada caráter. Destas, 1.200 fo ram referentes a cada grupo de cultivares estudado.

Foram escolhidos doze tamanhos amostrais, a saber: $5,10,15,20,25,30,35,40,45,50,55$ e 60 plantas por subpar cela. Cada um desses tamanhos amostrais foi considerado em 100 analises de variância, para um determinado caráter e grupo de cultivares.

As análises de variância seguiram o esquema apresentado na Tabela 1.

Para cada análise de variância, foi obtida uma estimativa do coeficiente de variação, ao nível de planta, por:

$$
c . v .=\frac{\sqrt{\frac{\hat{\sigma}_{n}^{2}}{L}+\hat{\sigma}_{e}^{2}}}{\hat{m}} \times 100
$$

ou

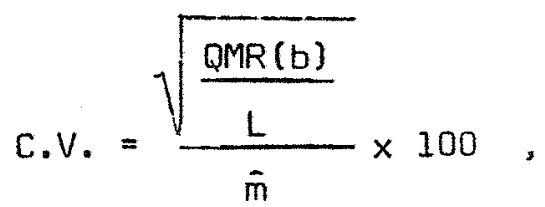

onde: $L=$ tamanho amostral, por subparcela. 
25.

\subsection{4 - Estudo de regressão}

0 estudo de regressão foi aplicado, aos dados simulados, visando determinar o coeficiente de variação em função do tamanho amostral, por subparcela.

$$
\text { Para cada caráter, foram considerados dois casos: }
$$

a) Por grupo de cultivares (Caso I);

b) 0 caráter, no total dos quatro grupos de cultivares (Caso II).

\subsubsection{1 - Modelo matemätico \\ 0 modelo matemático considerado: para os Casos I e II,}

foi :

$$
Y_{i j}=A+B X_{i j}+e_{i j}
$$

onde: $Y_{i j}=$ valores observados para os coeficientes de variação;

$A$ e $B=$ parámetros:

$x_{i j}=$ coeficientes (inverso do tamanho amostral, por subparce la):

$e_{i j}=$ erros aleatórios, onde se supõe $e_{i j} \cap N\left(0, \sigma^{2}\right)$.

Matricialmente o modelo matemático é:

$$
Y=X \beta+\varepsilon
$$

onde: $Y=$ vetor das observações;

$X=$ matriz dos coeficientes; 


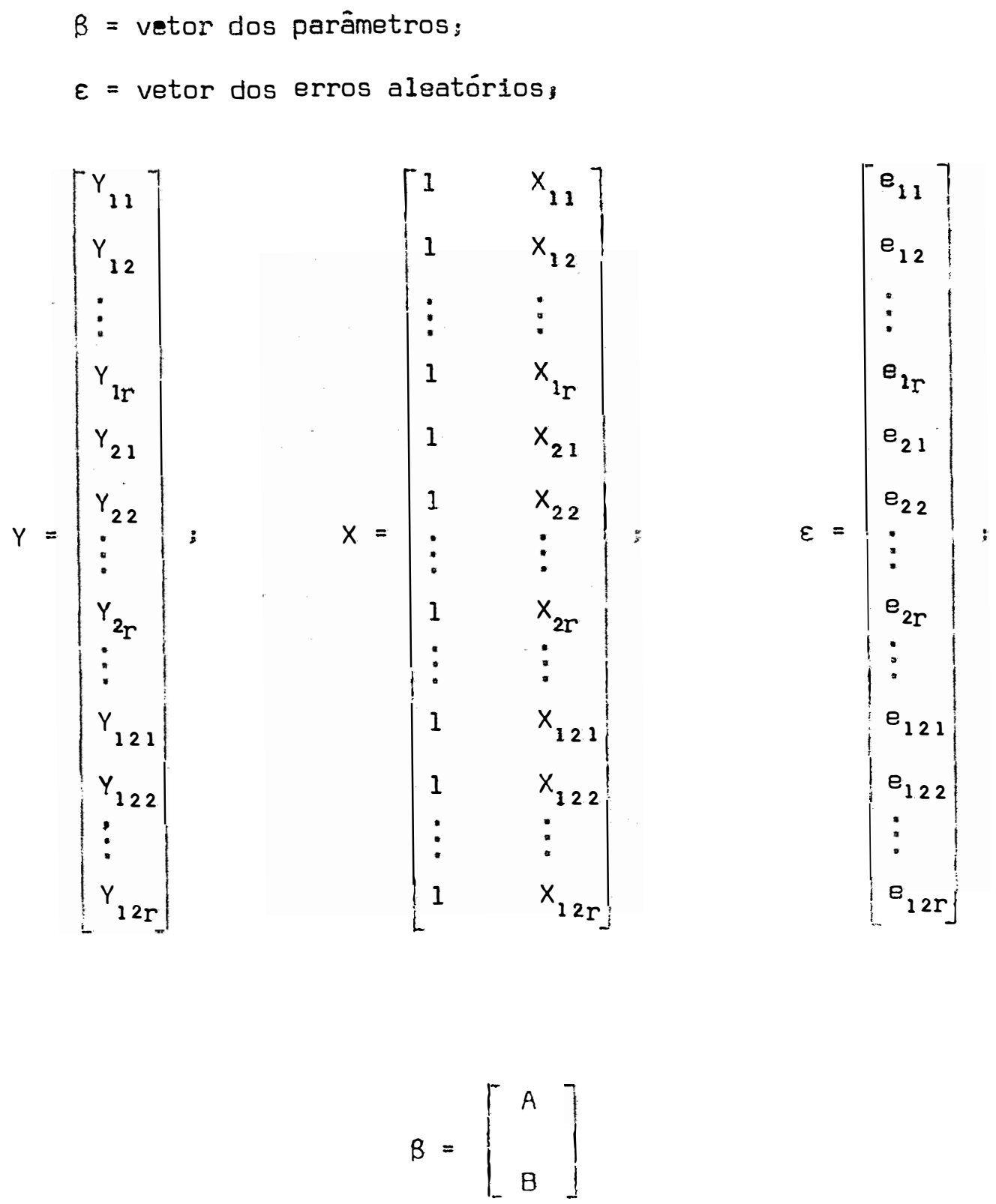

onde: $r=100$ para o Caso I:

$r=400$ para o Caso II. 


\subsubsection{2 - Estimativas dos parâmetros e suas vari âncias e covariâncias}

Os parâmetros da regressão foram estimados pelo método dos quadrados mínimos. O sistema de equações normais obtido foi:

$$
X \cdot X B=X \cdot Y
$$

onde:

$$
\begin{aligned}
& x^{\prime} X=s=\left[\begin{array}{cc}
12 r & r i x_{i} \\
r \sum x_{i} & r \sum x_{i}^{2}
\end{array}\right] \\
& \hat{B}=\left[\begin{array}{c}
\hat{A} \\
\hat{B}
\end{array}\right], \quad X^{\prime} Y=\left[\begin{array}{c}
\Sigma Y_{i} \\
\Sigma X_{i} Y_{i_{0}}
\end{array}\right]
\end{aligned}
$$

Como a matriz S é não singular, tem-se:

$$
s^{-1}=\frac{1}{12 r^{2} \sum X_{i}^{2}-r^{2}\left(\sum X_{i}\right)^{2}}\left[\begin{array}{cc}
r \sum X_{i}^{2} & -r \sum x_{i} \\
-r \sum X_{i} & 12 r
\end{array}\right]
$$

As estimativas dos parâmetros, obtidas de $\hat{\beta}=S^{-1} X^{\prime} Y$;

são :

$$
\bar{A}=\frac{\sum X_{i}^{2} \sum Y_{i}-\sum X_{i} \sum X_{i} Y_{i}}{12 r \sum X_{i}^{2}-r\left(\sum X_{i}\right)^{2}},
$$




$$
B=\frac{12 \sum X_{i} Y_{1}-\sum X_{i} \sum Y_{i}}{12 r \sum X_{i}^{2}-\Gamma\left(\sum X_{i}\right)^{2}} .
$$

Logo, a equação de regressão obtida foi:

$$
\hat{P}=\hat{A}+\hat{B} X .
$$

As variâncias e as covariâncias das estimativas dos parâmetros, obtidas da matriz de dispersão $D=S^{-1} \sigma^{2}$, são:

$$
\begin{aligned}
V(\hat{A}) & =\frac{\sum x_{i}^{2}}{12 r \sum x_{i}^{2}-r\left(\sum x_{i}\right)^{2}} \sigma^{2} ; \\
V(\theta) & =\frac{12}{12 r \sum x_{i}^{2}-r\left(\sum x_{i}\right)^{2}} \sigma^{2} ; \\
\operatorname{cov}(\bar{A}, \theta) & =\operatorname{cov}(\theta, \tilde{A})=-\frac{\sum x_{i}}{12 r \sum x_{i}^{2}-r\left(\sum x_{i}\right)^{2}} \sigma^{2}
\end{aligned}
$$

A variância $\sigma^{2}$ foi estimada pelo quadrado médio resi dual (QMR), obtido da anälise de variância $(4 \cdot 2 \cdot 4.4)$. Assim, as es.* timativas das variâncias e covariâncias das estimativas dos parâmetros, são:

$$
\begin{aligned}
\hat{\nabla}(\hat{A}) & =0,0017 \mathrm{~s}^{2} \\
\nabla(\hat{\theta}) & =0,3279 \mathrm{~s}^{2} \\
\operatorname{CôV}(\hat{A}, \hat{\theta}) & =-0,0170 \mathrm{~s}^{2},
\end{aligned}
$$

para o Caso I, e,

$$
\begin{aligned}
\hat{V}(\hat{A}) & =0,0004 \mathrm{~s}^{2} \\
\nabla(\hat{B}) & =0,0820 \mathrm{~s}^{2} \\
\operatorname{CÔV}(\hat{A}, \hat{B}) & =-0,0042 \mathrm{~s}^{2}
\end{aligned}
$$


29.

para o Caso II.

\subsubsection{3 - Intervalos de confiança para o coeficien te de variação}

As variâncias das estimativas do coeficiente de variação foram obtidas por:

$$
V\left(\hat{Y}_{i}\right)=V(\hat{A})+x_{i}^{2} V(\hat{B})+2 x_{i} \operatorname{COV}(\hat{A}, \hat{B})
$$

Os intervalos de confiança para os coeficientes de variação, ao nível de 5\% de probabilidade, admitindo-se distribuição aproximadamente normal e $t=2$, foram calculados de acordo com a Ta bela 6, para os dois Casos.

Tabela 6 - Intervalos de confiança para os coeficientes de variação, ao nível de $5 \%$ de probabilidade, e $t=2$, para os Casos $I$ e II.

\begin{tabular}{|c|c|c|}
\hline \multirow{2}{*}{$\begin{array}{l}\text { Tamanho amostral } \\
\text { (por subparcela) }\end{array}$} & \multicolumn{2}{|c|}{ Intervalo de Confiança } \\
\hline & Caso I & Caso II \\
\hline 5 & $\hat{\gamma} \pm 0,1791 \mathrm{~s}$ & $P \pm 0,0894 \mathrm{~s}$ \\
\hline 10 & $P \pm 0,0795 \mathrm{~s}$ & $p \pm 0,0390 \mathrm{~s}$ \\
\hline 15 & $\gamma \pm 0,0597 \mathrm{~s}$ & $\hat{\gamma} \pm 0,0286 \mathrm{~s}$ \\
\hline 20 & $\hat{Y} \pm 0,0573 \mathrm{~s}$ & $p \pm 0,0272 \mathrm{~s}$ \\
\hline 25 & $P \pm 0,0588 \mathrm{~s}$ & $p \pm 0,0279 \mathrm{~s}$ \\
\hline 30 & $p \pm 0,0610 \mathrm{~s}$ & $\hat{\gamma} \pm 0,02915$ \\
\hline 35 & $\gamma \pm 0,0631 \mathrm{~s}$ & $\hat{\gamma} \pm 0,0301 \mathrm{~s}$ \\
\hline 40 & $\phi \pm 0,0650 \mathrm{~s}$ & $\gamma \pm 0,0311 \mathrm{~s}$ \\
\hline 45 & $p \pm 0,0665 \mathrm{~s}$ & $\gamma \pm 0,0319 \mathrm{~s}$ \\
\hline 50 & $\varphi \pm 0,0679 \mathrm{~s}$ & $\hat{\gamma} \pm 0,0325 \mathrm{~s}$ \\
\hline 55 & $P \pm 0,0690 \mathrm{~s}$ & $\hat{\gamma} \pm 0,0331 \mathrm{~s}$ \\
\hline 60 & $P \pm 0,0700 \mathrm{~s}$ & $\hat{\gamma} \pm 0,0336 \mathrm{~s}$ \\
\hline
\end{tabular}


4.2.4.4 - Anälise de variância e coeficiente de determinação

As análises de variância, considerando-se a regressão, foram feitas, seguindo-se o esquema apresentado na Tabela 7.

Tabela 7 - Esquema da análise de variância, considerando-se a regressão, para os Casos I e II.

\begin{tabular}{lc}
\hline Causas de Variação & G.L. \\
\hline Regressão Linear & 1 \\
Desvios da Regressão & 10 \\
(Tratamentos) & $111)$ \\
Residuo & $12(r-1)$ \\
\hline o t a I & $12 r-1$ \\
\hline
\end{tabular}

Para testar-se a regressão linear e os desvios da re gressão, usaram-se:

$$
F=\frac{\text { QM Regressão Linear }}{\text { QMR }} \text {, }
$$

com 1 e $12(\Gamma-1)$ graus de liberdade,

$$
F=\frac{\text { QM Desvios da Regressão }}{\text { QMR }}
$$

com 10 e $12(r-1)$ graus de liberdade, respectivamente. 
Como, nos dois casos, os desvios da regressão não são necessariamente nulos, o coeficiente de determinação foi calculado por:

$$
\Gamma^{2}=\frac{S Q \text { Regressão Linear }}{\text { SQ Tratamentos }}
$$

Foi também calculado o coeficiente de determinação ajustado que, segundo HOFFMANN e VIEIRA (1977), é dado por:

$$
\overline{r^{2}}=r^{2}-\frac{1}{n-2}\left(1-r^{2}\right) \text {, }
$$

onde $n-2$ = número de graus de liberdade dos desvios da regressão.

\subsection{5 * Determinação do tamanho ótimo amostral \\ Para cada caráter foram determinados os seguintes ta} manhos ötimos amostrais:

a) Um para cada grupo de cultivares:

b) Um para o caráter, no total dos quatro grupos de cultivares. Em todos os casos, os tamanhos ótimos amostrais foram determinados pelo método da curvatura máxima (FEDERER, 1955). Consistiu em marcar-se em gráficos as estimativas dos coeficientes de variação, obtidas pela equação (6), em função dos respectivos ta manhos amostrais. por subparcela. Os tamanhos ótimos amostrais corresponderam às abscissas onde ocorreu a curvatura máxima, determinando-se esses pontos por inspeção visual. ponto de curvatura má- 
32.

xima é caracterizado pelo fato que, a partir dele, um aumento no ta manho da amostra proporciona um pequeno decréscimo no coeficiente de variação. 
33.

5. RESULTADOS

Para um melhor acompanhamento, os resultados são apre sentados por caráter.

\section{1 - Caráter Peso de 50 Grãos}

\subsection{1 - Anälise de variância dos dados simulados}

Devido ao gránde nümero de análises de variância, apresentam-se apenas os valores médios do quadrado médio do residuo (b), média do grupo e coeficiente de variação a nível de planta, ob tidos de 100 análises de variância, para todos os tamanhos amostrais. Esses valores são apresentados por grupo de cultivares, nas Tabelas: híbridos simples (Tabela 8), híbridos duplos (Tabela 9), variedades (Tabela 10) e compostos (Tabela 11). 
Tabela 8 - Carāter peso de 50 grãos $(\mathrm{g})$. Valores médios do quadrado médio do resíduo (b), média do grupo e coeficiente de va riação, a nível de planta, obtidos de 100 análises de vä riância, para os híbridos simples.

\begin{tabular}{cccc}
\hline $\begin{array}{c}\text { Tamanho amostral } \\
\text { (por subparcela) }\end{array}$ & \multicolumn{3}{c}{ Valor médio } \\
\cline { 2 - 4 } & QMR (b) & $\hat{\mathrm{m}}$ & $\mathrm{C} . \mathrm{V}_{0}(\%)$ \\
\hline 5 & 13,5305 & 12,0150 & 13,53 \\
10 & 20,5038 & 11,9827 & 11,79 \\
15 & 25,8619 & 11,9998 & 10,80 \\
20 & 31,5252 & 12,0068 & 10,34 \\
25 & 40,2077 & 11,9984 & 10,46 \\
30 & 42,5107 & 12,0349 & 9,74 \\
35 & 51,9881 & 12,0339 & 10,01 \\
40 & 56,4386 & 11,9843 & 9,80 \\
45 & 61,2811 & 11,9708 & 9,60 \\
50 & 71,2253 & 12,0280 & 9,80 \\
55 & 79,1589 & 12,0212 & 9,87 \\
60 & 81,7575 & 12,0021 & 9,62 \\
\hline
\end{tabular}

Tabela 9 - Caráter peso de 50 grãos $(\mathrm{g})$. Valores médios do quadrado médio do resíduo $(t)$, média do grupo e coeficiente de va riação, a nível de planta, obtidos de 100 análises de väriância, para os híbridos duplos.

\begin{tabular}{cccc}
\hline \multirow{2}{*}{$\begin{array}{c}\text { Tamanho amostral } \\
\text { (por subparcela) }\end{array}$} & \multicolumn{3}{c}{ Valor médio } \\
\cline { 2 - 4 } & QMR (b) & $\hat{\mathrm{m}}$ & C.V.(\%) \\
\hline 5 & 11,1654 & 12,9774 & 11,40 \\
10 & 12,3754 & 13,0219 & 8,45 \\
15 & 16,6150 & 12,9947 & 8,00 \\
20 & 18,7763 & 12,9787 & 7,37 \\
25 & 20,8958 & 12,9931 & 6,95 \\
30 & 24,6580 & 13,0139 & 6,84 \\
35 & 28,5059 & 13,0103 & 6,83 \\
40 & 28,7506 & 13,0029 & 6,43 \\
45 & 30,1217 & 13,0061 & 6,20 \\
50 & 35,5157 & 13,0199 & 6,39 \\
55 & 36,7101 & 12,9980 & 6,22 \\
60 & 41,0055 & 13,0137 & 6,26 \\
\hline
\end{tabular}


Tabela 10 - Caráter peso de 50 grãos ( $\mathrm{g}$ ). Valores médios do quadrado médio do resíduo (b), média do grupo e coeficiente de variação, a nível de planta, obtidos de 100 análises de variância, para as variedades.

\begin{tabular}{cccc}
\hline \multirow{2}{*}{$\begin{array}{c}\text { Tamanho amostral } \\
\text { (por subparcela) }\end{array}$} & \multicolumn{3}{c}{ Valor médio } \\
\cline { 2 - 4 } & QMR (b) & $\hat{m}$ & C.V. $(\%)$ \\
\hline 5 & 12,3023 & 13,9957 & 11,10 \\
10 & 15,6740 & 13,9913 & 8,83 \\
15 & 18,3888 & 13,9918 & 7,81 \\
20 & 22,6230 & 14,0066 & 7,51 \\
25 & 27,4825 & 14,0105 & 7,37 \\
30 & 30,5828 & 13,9696 & 7,13 \\
35 & 35,0946 & 14,0294 & 7,06 \\
40 & 38,1523 & 13,9978 & 6,90 \\
45 & 41,6945 & 13,9876 & 6,80 \\
50 & 44,9909 & 13,9829 & 6,70 \\
55 & 48,4669 & 14,0295 & 6,60 \\
60 & 53,4426 & 14,0112 & 6,64 \\
\hline
\end{tabular}

Tabela 11 - Caráter peso de 50 grãos $(g)$. Valores médios do quadrado médio do resíduo (b), média do grupo e coeficiente de variação, a nível de planta, obtidos de 100 análises de variância, para os compostos.

\begin{tabular}{cccc}
\hline \multirow{2}{*}{$\begin{array}{c}\text { Tamanio amostral } \\
\text { (por subparcela) }\end{array}$} & \multicolumn{3}{c}{ Valor médio } \\
\cline { 2 - 4 } & QMR (b) & $\hat{\mathrm{m}}$ & C.V. (\%) \\
\hline 5 & 15,1450 & 15,0174 & 11,43 \\
10 & 21,4820 & 14,9982 & 9,63 \\
15 & 26,8331 & 15,0007 & 8,79 \\
20 & 32,8792 & 14,9909 & 8,45 \\
25 & 40,1960 & 14,9424 & 8,35 \\
30 & 45,1050 & 14,9329 & 8,12 \\
35 & 51,9687 & 14,9891 & 8,03 \\
40 & 61,5190 & 14,9996 & 8,17 \\
45 & 63,4294 & 14,9656 & 7,82 \\
50 & 70,5293 & 14,9482 & 7,85 \\
55 & 77,5413 & 15,0023 & 7,80 \\
60 & 86,7380 & 14,9919 & 7,91 \\
\hline
\end{tabular}


36.

Na Tabela 12 encontram-se os valores médios das mëdias das cultivares, relativos a 100 anälises de variância, para to-dos os tamanhos amostrais.

Tabela 12 - Caráter peso de 50 grãos. Valores médios das médias das cultivares $(g)$,relativos a 100 análises de variância.

\begin{tabular}{|c|c|c|c|c|c|c|c|c|}
\hline \multirow{2}{*}{$\begin{array}{l}\text { Tamanho } \\
\text { amostral } \\
\text { (por sub } \\
\text { parcela) }\end{array}$} & \multicolumn{8}{|c|}{ Valor médio } \\
\hline & $\tilde{m}_{1}$ & $\hat{m}_{2}$ & $\hat{\mathrm{m}}_{3}$ & $\tilde{m}_{4}$ & $\tilde{m}_{5}$ & $\hat{\mathrm{m}}_{6}$ & $\hat{\mathrm{m}}_{7}$ & $\hat{m}_{8}$ \\
\hline 5 & 11,5617 & 12,4682 & 12,9362 & 13,0185 & 14,1459 & 13,8456 & 15 & 14,6629 \\
\hline 10 & 11,5518 & 12,4137 & 12,9325 & 13,1112 & 14,1176 & 13,8651 & 15,3081 & 14,6883 \\
\hline 15 & 11,6220 & 12,3775 & 12,9309 & 13,0585 & 14,1422 & $.13,8415$ & 15,3215 & 14,6799 \\
\hline 20 & 11,5971 & 12,4165 & 12,9371 & 13,0204 & 14,1723 & 13,8410 & 15.2995 & 14,6824 \\
\hline 25 & 11,5825 & 12,4142 & 12,9322 & 13,0540 & 14,1262 & 13.8949 & 15,2529 & 14.6318 \\
\hline 30 & 11,5924 & 12,4773 & 12,9796 & 13,0482 & 14,1332 & 13,8061 & 15,1863 & 14,6796 \\
\hline 35 & 11,6491 & 12,4187 & 12,9456 & 13,0750 & 14,2287 & 13,8302 & 15,2938 & 14,6845 \\
\hline 40 & 11,5913 & 12,3774 & 12,9532 & 13,0527 & 14,1329 & 13,8627 & 15,3057 & 14,6934 \\
\hline 45 & 11,5579 & $12 ; 3837$ & 12,9588 & 13,0535 & 14,1480 & 13,8273 & 15,2230 & 14,7082 \\
\hline 50 & 11,6639 & 12,3921 & 12,9355 & 13,1043 & 14,1577 & 13,8081 & 15,2578 & 14,6385 \\
\hline 55 & 11,6276 & 12,4148 & 12,9524 & 13,0436 & 14,1854 & 13,8737 & 15,2945 & 14,7100 \\
\hline 60 & 11,5843 & 12,4198 & 12,9718 & 13,0557 & 14,1375 & 13,8849 & 15,2941 & 14,6897 \\
\hline
\end{tabular}

onde: 1 e 2 são híbridos simples; 3 e 4 híbridos duplos; 5 e 6 variedades; 7 e 8 compostos, apresentados na mesma sequência de 4.1.1.

\subsection{2 * Anālise de variância dos coeficientes de variação e coeficiente de determinação}

As análises de variância dos coeficientes de variação. considerando-se a regressão, e os coeficientes de determinação, são apresentados nas seguintes Tabelas: Caso I (Tabelas de 13 a 16 ) e 6 a so II (Tabela 17). 
Tabela 13 - Caráter peso de 50 grãos. Análise de variância dos coeficientes de variação, considerando-se a regressão, e coeficiente de determinação apresentados pelos híbridos simples.

\begin{tabular}{lrrrr}
\hline Causas de Variação & G.L. & S.Q. & Q.M. & \multicolumn{1}{c}{ F } \\
\hline Regressão Linear & 1 & $1.435,0068$ & $1.435,0068$ & $508,54 \% *$ \\
Desvios da Regressão & 10 & 35,6999 & 3,5700 & 1,27
\end{tabular}

(Tratamentos)

(11) $(1.470,7067)$

$\begin{array}{llll}\text { Resíduo } & 1.188 & 3.352,3119 & 2,8218\end{array}$

Total $1.199 \quad 4.823,0186$

$* *$ = significativo ao nível de $1 \%$ de probabilidade;

$r^{2}=0,9757: \bar{r}^{2}=0,9733$.

Tabela 14 - Caráter peso de 50 grãos. Análise de variāncia dos coeficientes de variação, considerando-se a regressão, e coeficiente de determinação apresentados pelos híbridos duplos.

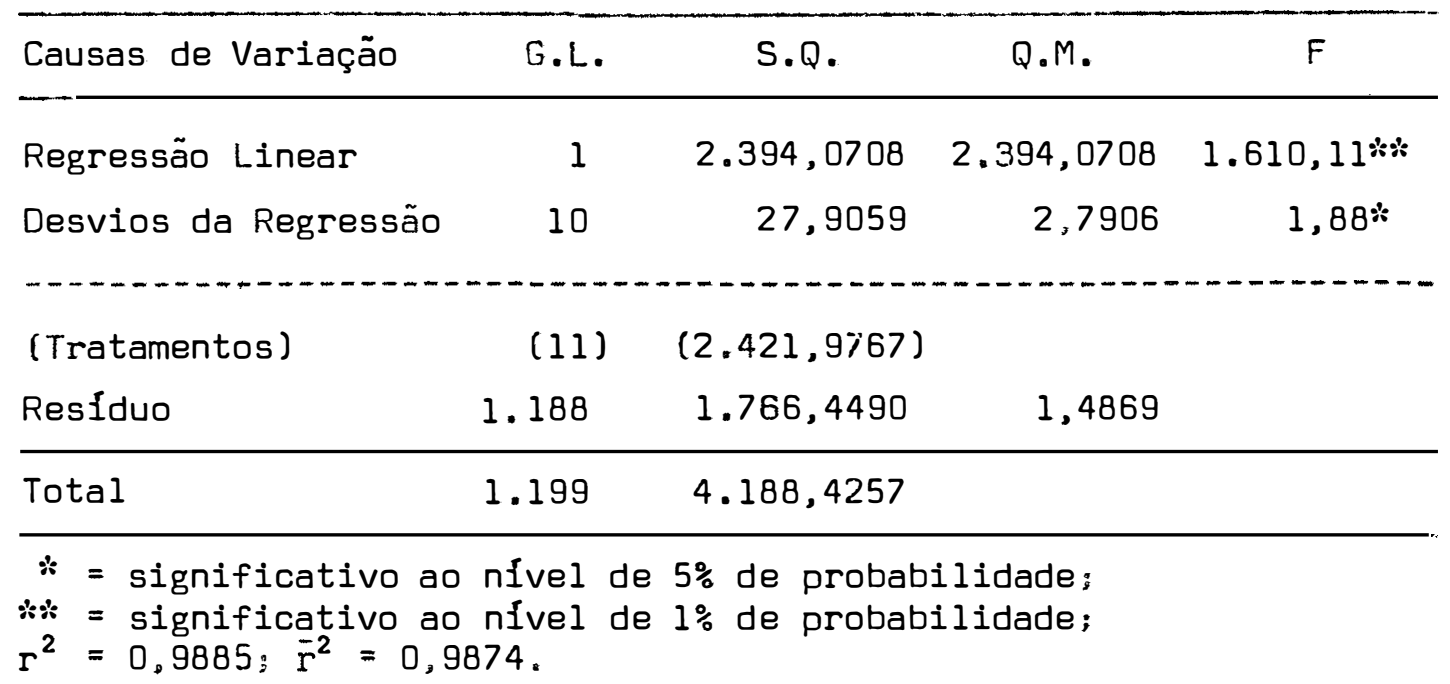


Tabela 15 - Caráter peso de 50 grãos. Análise de variância dos coeficientes de variação, considerando-se a regressão, e coeficiente de determinaçäo apresentados pelas variedades.

\begin{tabular}{lrrrrr}
\hline Causas de Variação & G.L. & S.Q. & \multicolumn{1}{c}{ Q.M. } & \multicolumn{1}{c}{ F } \\
\hline Regressão Linear & 1 & $1.812,6194$ & $1.812,6194$ & $1.196,76 * *$ \\
Desvios da Regressão & 10 & 6,9031 & 0,6903 & 0,46
\end{tabular}

(Tratamentos)

(11) $(1.819,5225)$

Resíduo

$1.188 \quad 1.799,3579$

1,5146

Total

$1.199 \quad 3.618,8804$

$* *$ = significativo ao nível de $1 \%$ de probabilidade;

$r^{2}=0,9962 ; \bar{r}^{2}=0,9958$.

Tabela 16 - Caráter peso de 50 grãos. Análise de variância dos coeficientes de variação, considerando-se a regressão, e coeficiente de determinação apresentados pelos compostos.

\begin{tabular}{|c|c|c|c|c|}
\hline Causas de Variação & G.L. & $S \cdot Q$. & $Q . M$. & $F$ \\
\hline Regressão Linear & 1 & $1.206,9317$ & $1.206,9317$ & $593,50 * *$ \\
\hline Desvios da Regressão & 10 & 8,8575 & 0,8858 & 0,44 \\
\hline 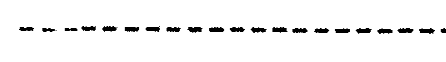 & $\cdots \cdots-\cdots$ & $\cdots-n-m-n-\cdots$ & $\cdots-\cdots-\cdots$ & $\cdots-\cdots-n$ \\
\hline (Tratamentos) & $(11)$ & $(1.215,7892)$ & & \\
\hline Resíduo & 1.188 & $2.415,8929$ & 2,0336 & \\
\hline Total & 1.199 & $3.631,6821$ & & \\
\hline
\end{tabular}


Tabela 17 - Caräter peso de 50 gräos. Anälise de variância dos coeficientes de variação, considerando-se a regressão, e coeficiente de determinação apresentados por este caráter (Caso II).

\begin{tabular}{lcrrr}
\hline Causas de Variação & G.L. & S.Q. & Q.M. & F \\
\hline Regressão Linear & 1 & $6.745,2069$ & $6.745,2069$ & $1.907,20 * \%$ \\
Desvios da Regressão & 10 & 23,6731 & 2,3673 & 0,67 \\
\hline (Tratamentos) & $(11)$ & $(6.768,8800)$ & \\
Residuo & 4.788 & $16.933,7081$ & 3,5367 \\
\hline Total & 4.799 & $23.702,5881$ & \\
\hline$* *=$ significativo ao nível de $1 \%$ de probabilidade; \\
$r^{2}=0,9965: \bar{r}^{2}=0,9962$.
\end{tabular}

\section{1 .3 Equações de regressão}

As equações de regressão, obtidas para o caráter peso de 50 grãos, foram:

(a) $\hat{Y}=9,3247+21,6916 X$,

para os híbridos simples:

(b) $\quad \beta=5,8291+28,0177 x$.

para os híbridos duplos;

(c) $\quad \beta=5,2765+24,3791 X$,

para as variedades: 
40 .

(d)

$$
\varphi=7,5002+19,8932 \times \text {, }
$$

para os compostos:

(e)

$$
P=7,2337+23,5143 x
$$

para este caráter (Caso II).

\subsection{4 - Estimativas do coeficiente de variação e respecti- vos intervalos de confiança}

As estimativas do coeficiente de variação, obtidas pelas equações de regressão (5.1.3), e seus respectivos intervalos de confiança são apresentados na Tabela 18, para os Casos I e II.

Tabela 18 - Caráter peso de 50 grãos. Estimativas do coeficiente de variação $(\%)$ e seus respectivos intervalos de confiança, ao nível de $5 \%$ de probabilidade, e $t=2$, obtidos para os Casos I e II.

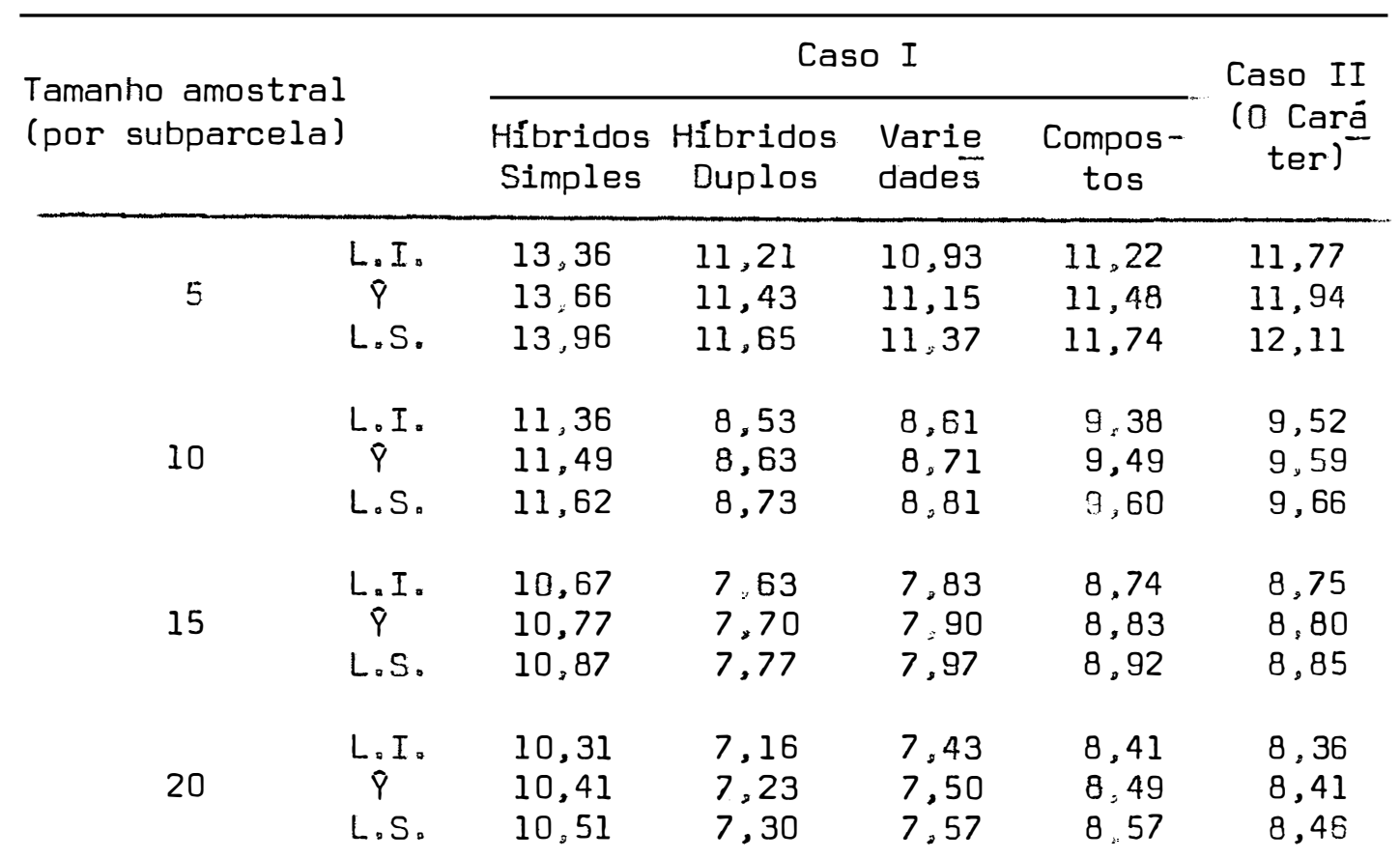




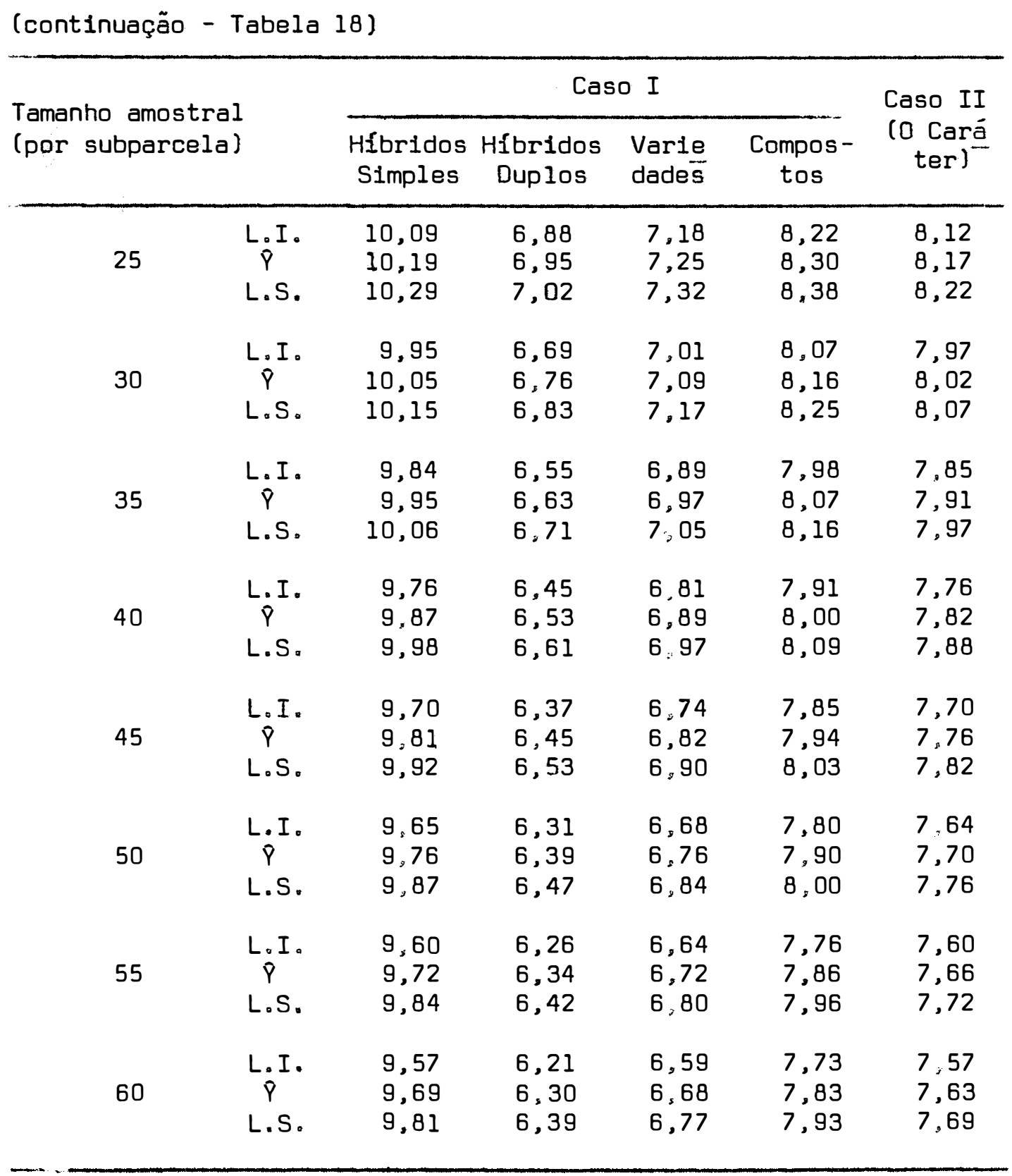


5.1 .5 - Representação gräfica das equações de regressão

A partir dos valores da Tabela 18, foram construidos os gräficos das equações de regressäo (5.1.3), os quais são apresen tados nas seguintes Figuras: híbridos simples (Figura 1), híbridos duplos (Figura 2), variedades (Figura 3), compostos (Figura 4) e o caráter (Figura 5)。

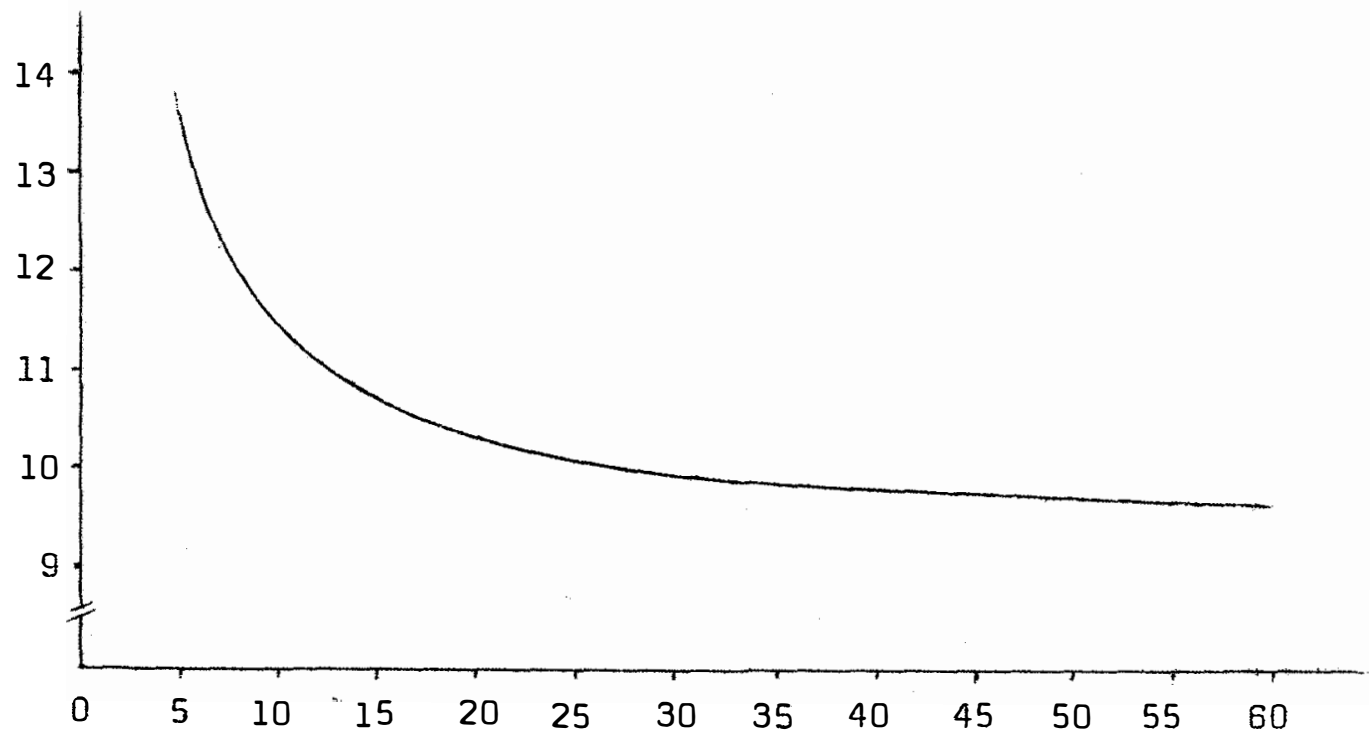

Figura 1 - Caráter peso de 50 grãos. Gráfico da equação $\bar{\gamma}=9,3247+21.6916 x$, obtida para os híbri dos simples. 
43.

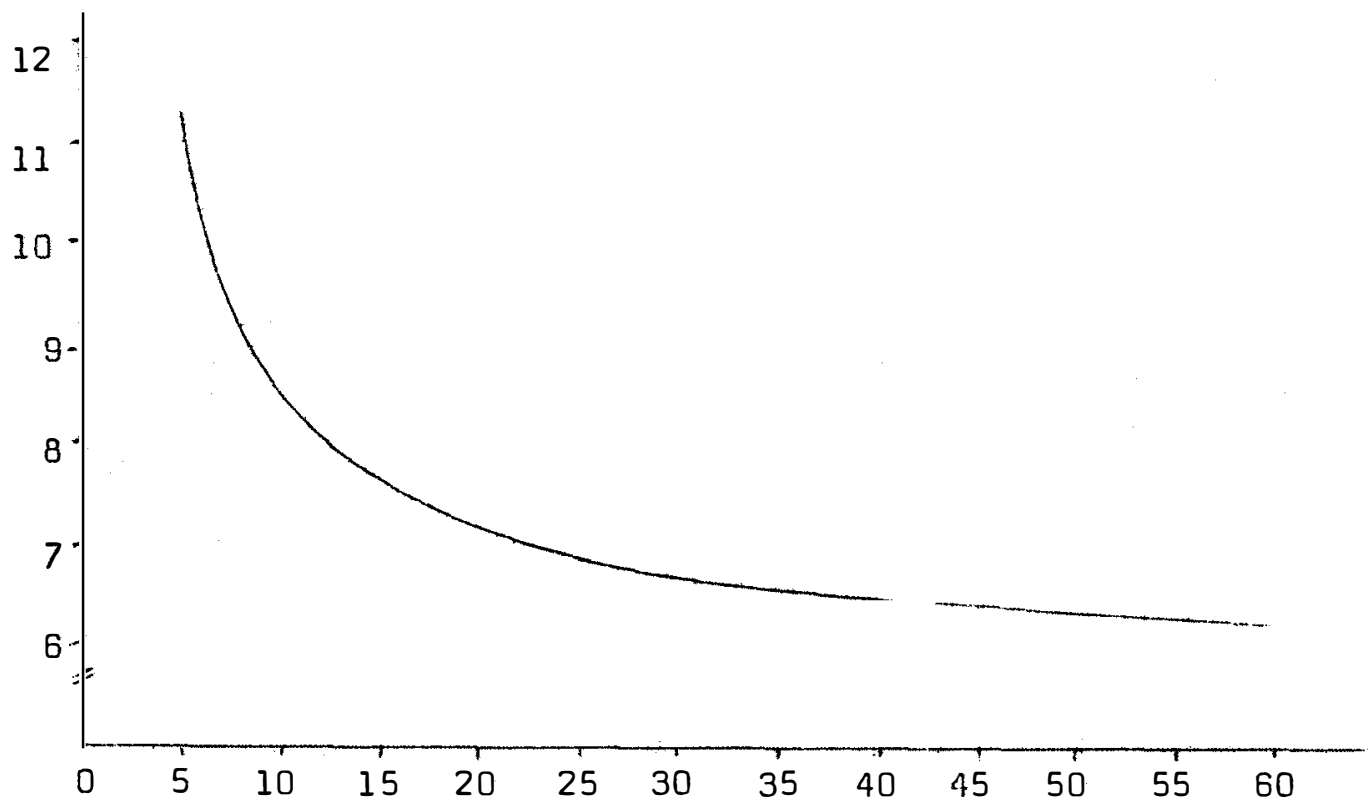

Figura 2 - Caräter peso de 50 grãos. Gräfico da equação $\hat{Y}=5,8291+28,0177 X$, obtida para os híbri dos duplos.

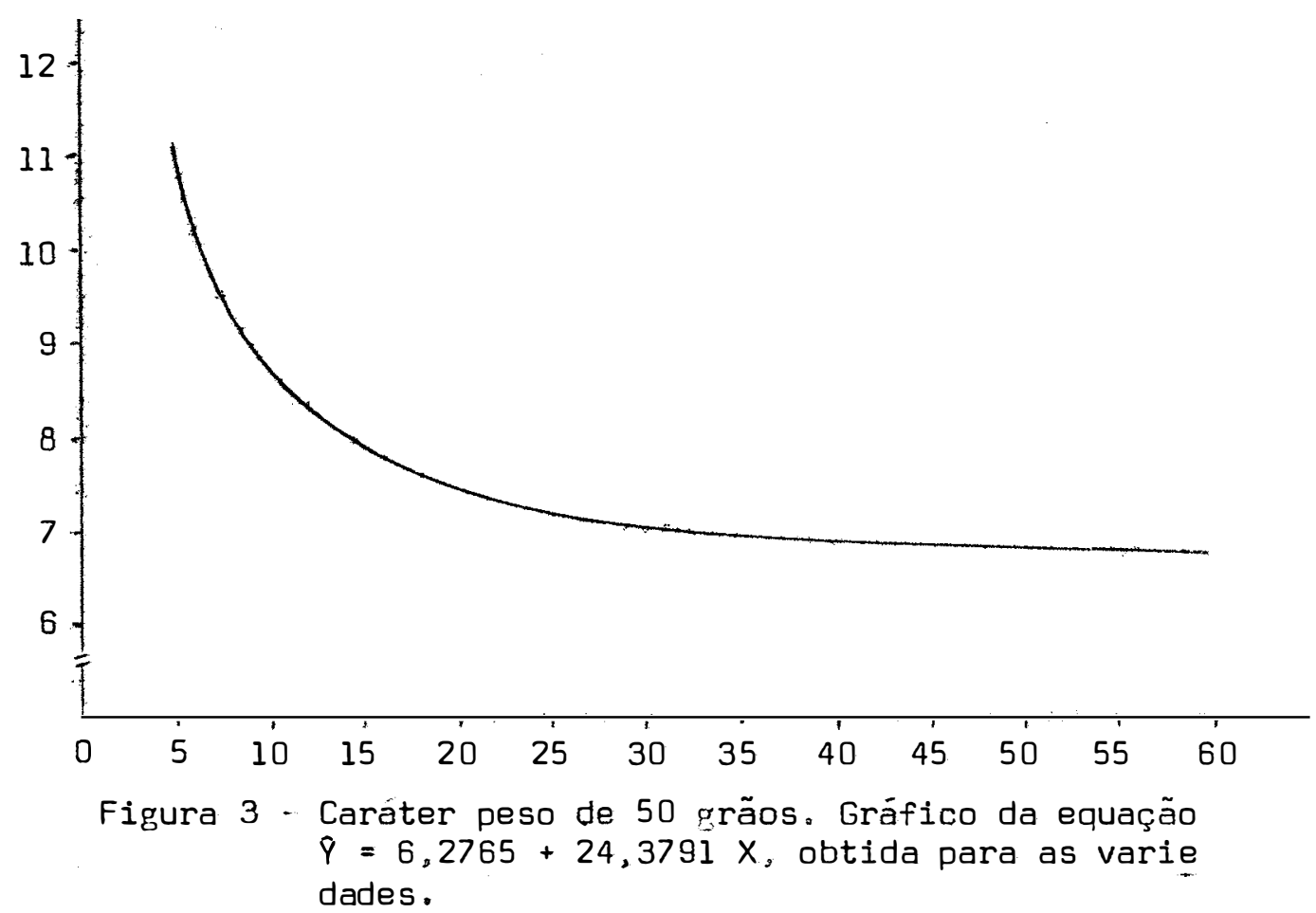


44.
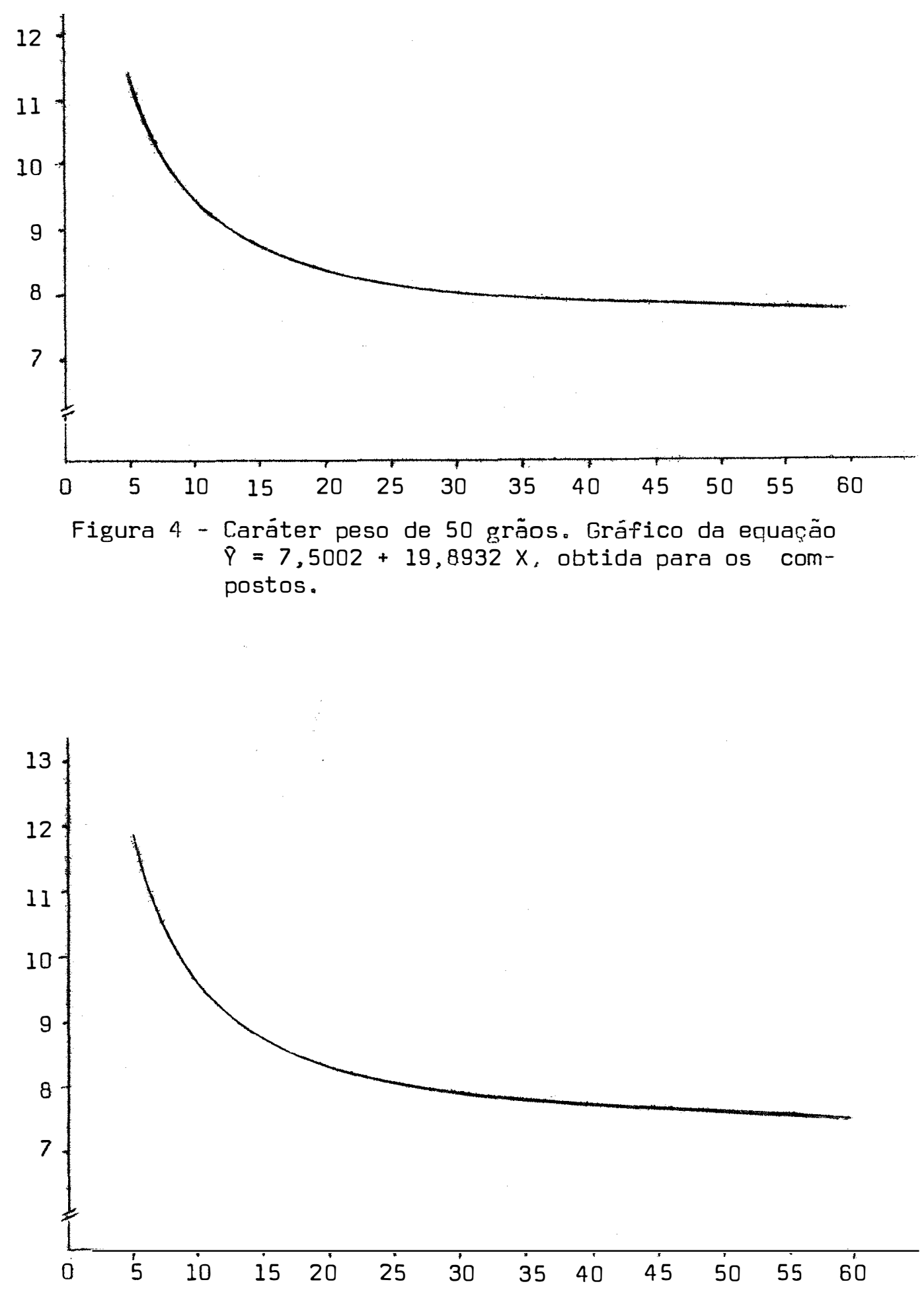

Figura 5 - Caráter peso de 50 grãos. Gräfico da equação $Y=7.2337+23,5143 \mathrm{X}$, obtida para este caráter (no total dos quatro grupos). 


\section{2 - Caräter Peso de Espiga}

\subsection{1 - Análise de variância dos dados simulados}

Seguindo-se o mesmo procedimento de 5.1.1, apresentam-se nas Tabelas de 19 a 22, os valores médios do quadrado médio do resíduo (b), média do grupo e coeficiente de variação a nível de planta, obtidos para os híbridos simples, híbridos duplos, variedades e compostos, respectivamente.

Na Tabela 23 encontram-se os valores médios das médias das cultivares, relativos a 100 análises de variância, para todos os tamanhos amostrais.

Tabela 19 - Caráter peso de espiga (g), Valores médios do quadrado médio do resíduo (b), média do grupo e coeficiente de variação, a nível de planta, obtidos de 100 análises de variância, para os híbridos simples.

\begin{tabular}{cccc}
\hline \multirow{2}{*}{$\begin{array}{c}\text { Tamanho amostral } \\
\text { (por subparcela) }\end{array}$} & \multicolumn{3}{c}{ Valor médio } \\
\cline { 2 - 4 } & QMR (b) & $\hat{m}$ & C.V. $(\%)$ \\
\hline 5 & $2.206,0489$ & 114,5012 & 18,14 \\
10 & $3.045,2509$ & 113,8709 & 15,15 \\
15 & $3.769,4579$ & 114,1940 & 13,73 \\
20 & $4.336,1345$ & 114,1833 & 12,76 \\
25 & $5.249,2446$ & 114,4311 & 12,51 \\
30 & $5.899,5773$ & 115,1834 & 12,03 \\
35 & $6.797,0063$ & 114,3965 & 12,08 \\
40 & $7.559,2958$ & 114,1771 & 11,92 \\
45 & $8.700,4056$ & 114,3694 & 12,02 \\
50 & $8.912,5221$ & 114,2670 & 11,58 \\
55 & $10.003,3581$ & 113,7374 & 11,70 \\
60 & $10.768,2168$ & 113,6847 & 11,65 \\
\hline
\end{tabular}


Tabela 20 - Caráter peso de espiga ( $\mathrm{g}$ ) a Valores médios do quadrado médio do resíduo (b), média do grupo e coeficiente de variação, a nível de planta, obtidos de 100 análises de variância, para os híbridos duplos.

\begin{tabular}{cccc}
\hline $\begin{array}{c}\text { Tamantio amostral } \\
\text { (por subparcela) }\end{array}$ & \multicolumn{3}{c}{ Valor médio } \\
\cline { 2 - 4 } & QMR (b) & $\tilde{m}$ & C.V. $\%$ ) \\
\hline 5 & $3.093,0822$ & 135,3272 & 18,15 \\
10 & $3.850,8420$ & 135,7122 & 14,28 \\
15 & $4.491,7921$ & 134,8217 & 12,67 \\
20 & $5.276,6804$ & 134,7583 & 11,95 \\
25 & $5.974,1375$ & 135,1621 & 11,31 \\
30 & $6.975,3593$ & 134,5781 & 11,22 \\
35 & $7.475,8865$ & 134,7625 & 10,71 \\
40 & $7.876,1712$ & 134,8092 & 10,31 \\
45 & $8.649,8939$ & 135,1463 & 10,14 \\
50 & $9.984,3586$ & 135,6316 & 10,28 \\
55 & $10.673,9009$ & 134,6094 & 10,23 \\
60 & $11.367,5400$ & 134,7780 & 10,07 \\
\hline
\end{tabular}

Tabele 21 - Caräter peso de espiga $(g)$. Valores médios do quadrado médio do residuo (b), média do grupo e coeficiente de variação, a nível de planta, obtidos de 100 análises de variância, para as variedades.

\begin{tabular}{cccc}
\hline $\begin{array}{c}\text { Tamanho amostral } \\
\text { (por subparcela) }\end{array}$ & QMR (b) & $\hat{m}$ & Valor médio \\
& $4.748,8351$ & 139,8004 & 21,79 \\
5 & $7.173,7338$ & 140,6221 & 18,80 \\
10 & $9.379,0950$ & 140,1458 & 17,60 \\
15 & $11.650,1925$ & 140,0565 & 16,96 \\
20 & $13.958,0655$ & 140,1345 & 16,61 \\
25 & $16.553,3435$ & 139,9920 & 16,61 \\
30 & $19.243,7943$ & 140,0164 & 16,47 \\
35 & $22.581,8791$ & 140,0203 & 16,73 \\
40 & $24.383,9354$ & 140,5724 & 16,32 \\
45 & $26.288,6246$ & 138,9179 & 16,32 \\
50 & $28.626,5538$ & 139,7776 & 16,16 \\
55 & $31.779,9325$ & 139,9316 & 16,21 \\
60 & & & \\
\hline
\end{tabular}


Tabela 22 - Caráter peso de espiga (g). Valores médios do quadrado médio do residuo (b), média do grupo e coeficiente de variação, a nível de planta, obtidos de 100 análises de variāncia, para os compostos.

\begin{tabular}{cccc}
\hline \multirow{2}{*}{$\begin{array}{c}\text { Tamanho amostral } \\
\text { (por subparcela) }\end{array}$} & QMR (b) & $\hat{\mathrm{m}}$ & C.V. (\%) \\
\cline { 2 - 4 } & $2.329,4963$ & 137,8161 & 15,47 \\
\hline 5 & $2.412,5399$ & 138,0977 & 11,17 \\
10 & $2.551,8520$ & 137,8440 & 9,31 \\
15 & $2.840,5352$ & 138,0957 & 8,52 \\
20 & $3.136,9142$ & 138,0067 & 8,00 \\
25 & $3.414,2951$ & 137,5038 & 7,66 \\
30 & $3.649,6831$ & 137,7696 & 7,32 \\
35 & $3.575,2905$ & 137,9351 & 6,76 \\
40 & $4.029,4454$ & 137,9365 & 6,78 \\
45 & $4.008,6139$ & 137,6794 & 6,39 \\
50 & $4.545,7072$ & 138,1478 & 6,50 \\
55 & $4.561,7522$ & 138,0022 & 6,23 \\
60 & & & \\
\hline
\end{tabular}

Tabela 23 - Caráter peso de espiga. Valores médios das médias das cultivares $(\mathrm{g})$,relativos a 100 anälises de variāncia.

\begin{tabular}{cccccccccc}
\hline $\begin{array}{c}\text { Tamanho } \\
\text { amostral } \\
\text { (por sub } \\
\text { parcela) }\end{array}$ & $\hat{m}_{1}$ & & $\hat{m}_{2}$ & $\hat{m}_{3}$ & $\hat{m}_{4}$ & $\hat{m}_{5}$ & $\hat{m}_{6}$ & $\hat{m}_{7}$ & $\hat{m}_{8}$ \\
\hline 5 & 109,3499 & 119,6524 & 140,2231 & 130,4312 & 138,0851 & 141,5157 & 145,3487 & 130,2835 \\
10 & 108,9434 & 118,7985 & 140,8246 & 130,5998 & 137,8979 & 143,3462 & 146,0611 & 130,1343 \\
15 & 109,8803 & 118,5077 & 139,1563 & 130,4871 & 137,5280 & 142,7637 & 145,9177 & 129,7703 \\
20 & 109,6066 & 118,7601 & 139,5029 & 130,0138 & 137,8889 & 142,2241 & 146,0837 & 130,1078 \\
25 & 110,9870 & 117,8752 & 139,9454 & 130,3789 & 137,3031 & 142,9660 & 145,1457 & 130,8677 \\
30 & 110,0259 & 120,3410 & 138,5820 & 130,5742 & 137,2556 & 142,7285 & 145,8247 & 129,1831 \\
35 & 110,1962 & 118,5969 & 139,3072 & 130,2179 & 137,6797 & 142,3531 & 145,3966 & 130,1427 \\
40 & 109,4914 & 118,8628 & 139,4033 & 130,2152 & 137,4377 & 142,6031 & 145,6053 & 130,2650 \\
45 & 110,1073 & 118,6316 & 139,9109 & 130,3819 & 138,4745 & 142,6704 & 145,6140 & 130,2591 \\
50 & 110,5867 & 117,9472 & 140,5015 & 130,7618 & 136,6320 & 141,2039 & 145,3035 & 130,0554 \\
55 & 109,2773 & 118,1975 & 139,4513 & 129,7677 & 137,2011 & 142,3542 & 146,2591 & 130,0367 \\
60 & 109,2146 & 118,1548 & 139,6353 & 129,9208 & 137,4263 & 142,4370 & 145,9049 & 130,0997
\end{tabular}

onde: 1 e 2 são híbridos simples: 3 e 4 híbridos duplos 5 e 6 variedades: 7 e 8 compostos, apresentadas na mesma sequência de 4.1.1. 


\subsection{2 - Anălise de variância dos coeficientes de variação e coeficiente de determinação}

As análises de variância dos coeficientes de variação, considerando-se a regressão, e os coeficientes de determinação encontram-se nas seguintes Tabelas: Caso I (Tabelas de 24 a 27) e Caso II (Tabela 28).

Tabela 24 - Caráter peso de espiga. Análise de variância dos coeficientes de variação, considerando-se a regressão, e coe ficiente de determinação apresentados pelos híbridos sim ples.

\begin{tabular}{lrrrr}
\hline Causas de Variação & G.L. & \multicolumn{1}{c}{ S.Q. } & Q.M. & F \\
\hline Regressão Linear & 1 & $4.082,8241$ & $4.082,8241$ & $849,05 \% \%$ \\
Desvios da Regressão & 10 & 44,3051 & 4,4305 & 0,92 \\
\hdashline (Tratamentos) & $(11)$ & $(4.127,1292)$ & \\
Resíduo & 1.188 & $5.712,7602$ & 4,8087 \\
\hline Totai & 1.199 & $9.839,8894$ & & \\
\hline
\end{tabular}

$* *$ = significativo ao nível de $1 \%$ de probabilidade;

$r^{2}=0,9893 ; \bar{r}^{2}=0,9882$. 
Tabela 25 - Caräter peso de espiga. Análise de variância dos coeficientes de variação, considerando-se a regressão, e coe ficiente de determinação apresentados pelos híbridos du plos.

\begin{tabular}{|c|c|c|c|c|}
\hline Causas de Variação & G.L. & S.Q. & Q.M. & $\mathrm{F}$ \\
\hline Regressão Linear & 1 & $6.117,9040$ & $6.117,9040$ & $1.644,07 * *$ \\
\hline Desvios da Regressão & 10 & 57,5227 & 5,7523 & 1,55 \\
\hline \multicolumn{5}{|c|}{ 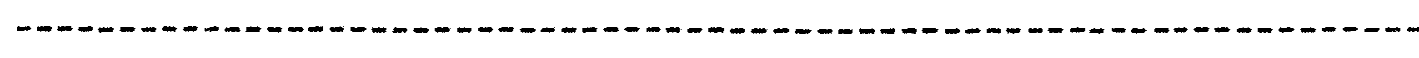 } \\
\hline (Tratamentos) & $(11)$ & $(6.175,4267)$ & & \\
\hline Resíduo & 1.188 & $4.420,7859$ & 3,7212 & \\
\hline Total & 1.199 & $10.596,2126$ & & \\
\hline
\end{tabular}

Tabela 26 - Caráter peso de espiga. Análise de variância dos coeficientes de variação, considerando-se a regressão, e coe ficiente de determinação apresentados pelas variedades.

\begin{tabular}{|c|c|c|c|c|}
\hline Causas de Variação & G.L. & $S . Q$. & Q.M. & $\mathrm{F}$ \\
\hline Regressão Linear & 1 & $2.865,8708$ & $2.865,8708$ & $340,41 * \%$ \\
\hline Desvios da Regressão & 10 & 24,4792 & 2,4479 & $0,29 \%$ \\
\hline \multicolumn{5}{|c|}{ 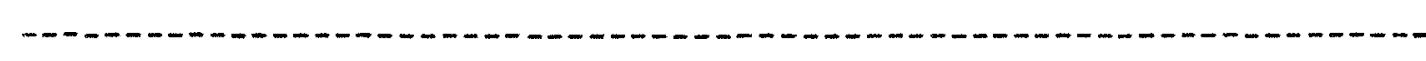 } \\
\hline (Tratamentos) & $(11)$ & $(2.890,3500)$ & & \\
\hline Resíduo & 1.188 & $10.001,7094$ & 8,4189 & \\
\hline Total & 1.199 & $12.892,0594$ & & \\
\hline \multicolumn{5}{|c|}{$\begin{aligned} * & =\text { significativo ao nível de } 5 \% \text { de probabilidade; } \\
* * & =\text { significativo ao nível de } 1 \% \text { de probabilidade; } \\
r^{2} & =0,9915 ; \bar{r}^{2}=0,9907 .\end{aligned}$} \\
\hline
\end{tabular}


Tabela 27 - Caráter peso de espiga. Análise de variância dos coeficientes de variação, considerando-se a regressão, e coe ficiente de determinação apresentados pelos compostos.

\begin{tabular}{lrrrr}
\hline Causas de Variação & G.L. & S.Q. & Q.M. & F \\
\hline Regressão Linear & 1 & $7.714,5059$ & $7.714,5059$ & $3.837,11 * *$ \\
Desvios da Regressão & 10 & 86,2566 & 8,6257 & $4,29 * *$ \\
(Tratamentos) & $(11)$ & $(7.800,7625)$ & \\
Resíduo & 1.188 & $2.388,5134$ & 2,0105 \\
\hline Total & 1.199 & $10.189,2759$ & \\
\hline$* *=$ significativo ao nível de $1 \%$ de probabilidade; \\
$\mathbf{r}^{2}=0,9889 ; \bar{r}^{2}=0,9878$.
\end{tabular}

Tabela 28 - Caráter peso de espiga. Análise de variância dos coeficientes de variação, considerando-se a regressão, e coe ficiente de determinação apresentados por este caräter (Caso II).

\begin{tabular}{lrrrr}
\hline Causas de Variação & G.L. & S.Q. & Q.M. & F \\
\hline Regressão Linear & 1 & $20.093,7077$ & $20.093,7077$ & $1.343,58 * *$ \\
Desvios da Regressão & 10 & 85,1723 & 8,5172 & 0,57 \\
& $(11)$ & $(20.178,8800)$ & \\
(Tratamentos) & 4.788 & $71.606,6343$ & 14,9554 \\
Resíduo & 4.799 & $91.785,5143$ & \\
\hline Total & n* $=$ significativo ao nivel de $1 \%$ de probabilidade; \\
$r^{2}=0,9958 ; \bar{r}^{2}=0,9954$. &
\end{tabular}




\subsection{3 - Equações de regressão}

As equações de regressão, obtidas para o caräter peso de espiga, foram:

$$
\text { (a) } \quad \gamma=11,0466+36,5885 x \text {, }
$$

para os híbridos simples;

(b) $\quad P=9,4600+44,7884 x$,

para os híbridos duplos;

(c) $\quad P=15,6294+30,6544 x$,

para as variedades;

$$
\text { (d) } \quad P=5,7410+50,2943 x \text {. }
$$

para os compostos:

$$
\text { (8) } \quad P=10,4707+40,5849 x \text {, }
$$

para este caräter (Caso II).

5.2.4 - Estimativas do coeficiente de variação e respectivos intervalos de confiança

As estimativas do coeficiente de variação, obtidas pelas equações de regressão $(5.2 .3)$, e seus respectivos intervalos de confiança são apresentadas na Tabela 29, para os Casos I e II. 
Tabela 29 - Caráter peso de espiga. Estimativas do coeficiente de va riação $(\%)$ e respectivos intervalos de confiança, ao nível de $5 \%$ de probabilidade, e $t=2$, obtidos para os Casos I e II.

\begin{tabular}{|c|c|c|c|c|c|c|}
\hline \multirow{2}{*}{$\begin{array}{l}\text { Tamanho amostral } \\
\text { (por subparcela) }\end{array}$} & & \multicolumn{4}{|c|}{ Caso I } & \multirow{2}{*}{$\begin{array}{c}\text { Caso II } \\
\text { (O Carä } \\
\text { ter })\end{array}$} \\
\hline & & $\begin{array}{l}\text { Híbridos } \\
\text { Simples }\end{array}$ & $\begin{array}{l}\text { Híbridos } \\
\text { Duplos }\end{array}$ & Varie & $\begin{array}{l}\text { Compos- } \\
\text { tos }\end{array}$ & \\
\hline 5 & $\begin{array}{l}\text { L.I. } \\
\text { L.S. }\end{array}$ & $\begin{array}{l}17,97 \\
18,36 \\
18,75\end{array}$ & $\begin{array}{l}18,07 \\
18,42 \\
18,77\end{array}$ & $\begin{array}{l}21,24 \\
21,76 \\
22,28\end{array}$ & $\begin{array}{l}15,55 \\
15,80 \\
16,05\end{array}$ & $\begin{array}{l}18,24 \\
18,59 \\
18,94\end{array}$ \\
\hline 10 & $\begin{array}{c}L . I . \\
P . S .\end{array}$ & $\begin{array}{l}14,54 \\
14,71 \\
14,88\end{array}$ & $\begin{array}{l}13,79 \\
13,94 \\
14,09\end{array}$ & $\begin{array}{l}18,46 \\
18,69 \\
18,92\end{array}$ & $\begin{array}{l}10,66 \\
10,77 \\
10,88\end{array}$ & $\begin{array}{l}14,38 \\
14,53 \\
14,68\end{array}$ \\
\hline 15 & $\begin{array}{l}\text { L.I. } \\
P \\
L . S .\end{array}$ & $\begin{array}{l}13,36 \\
13,49 \\
13,62\end{array}$ & $\begin{array}{l}12,33 \\
12,45 \\
12,57\end{array}$ & $\begin{array}{l}17,51 \\
17,68 \\
17,85\end{array}$ & $\begin{array}{l}9,02 \\
9,10 \\
9,18\end{array}$ & $\begin{array}{l}13,07 \\
13,18 \\
13,29\end{array}$ \\
\hline 20 & $\begin{array}{l}L_{0} I . \\
P . S .\end{array}$ & $\begin{array}{l}12,75 \\
12,88 \\
13,01\end{array}$ & $\begin{array}{l}11,59 \\
11,70 \\
11,81\end{array}$ & $\begin{array}{l}16,99 \\
17,16 \\
17,33\end{array}$ & $\begin{array}{l}8,18 \\
8,26 \\
8,34\end{array}$ & $\begin{array}{l}12,39 \\
12,50 \\
12,61\end{array}$ \\
\hline 25 & $\begin{array}{c}L . I . \\
P \\
L . S .\end{array}$ & $\begin{array}{l}12,38 \\
12,51 \\
12,64\end{array}$ & $\begin{array}{l}11,14 \\
11,25 \\
11,36\end{array}$ & $\begin{array}{l}16,69 \\
16,86 \\
17,03\end{array}$ & $\begin{array}{l}7,67 \\
7,75 \\
7,83\end{array}$ & $\begin{array}{l}11,98 \\
12,09 \\
12,20\end{array}$ \\
\hline 30 & $\begin{array}{c}L_{0} I_{0} \\
P \\
L . S .\end{array}$ & $\begin{array}{l}12,14 \\
12,27 \\
12,40\end{array}$ & $\begin{array}{l}10,83 \\
10,95 \\
11,07\end{array}$ & $\begin{array}{l}16,47 \\
16,65 \\
16,83\end{array}$ & $\begin{array}{l}7,33 \\
7,42 \\
7,51\end{array}$ & $\begin{array}{l}11,71 \\
11,82 \\
11,93\end{array}$ \\
\hline 35 & $\begin{array}{c}L . I . \\
P \\
L . S .\end{array}$ & $\begin{array}{l}11,95 \\
12,09 \\
12,23\end{array}$ & $\begin{array}{l}10,62 \\
10,74 \\
10,86\end{array}$ & $\begin{array}{l}16,33 \\
16,51 \\
16,69\end{array}$ & $\begin{array}{l}7,09 \\
7,18 \\
7,27\end{array}$ & $\begin{array}{l}11,51 \\
11,63 \\
11,75\end{array}$ \\
\hline 40 & $\begin{array}{c}L_{0} I . \\
P \\
L . S .\end{array}$ & $\begin{array}{l}11,82 \\
11,96 \\
12,10\end{array}$ & $\begin{array}{l}10,45 \\
10,58 \\
10,71\end{array}$ & $\begin{array}{l}16,21 \\
16,40 \\
16,59\end{array}$ & $\begin{array}{l}6,91 \\
7,00 \\
7,09\end{array}$ & $\begin{array}{l}11,37 \\
11,49 \\
11,61\end{array}$ \\
\hline 45 & $\begin{array}{l}L . I_{0} \\
L . S .\end{array}$ & $\begin{array}{l}11,71 \\
11,86 \\
12,01\end{array}$ & $\begin{array}{l}10,32 \\
10,45 \\
10,58\end{array}$ & $\begin{array}{l}16,12 \\
16,31 \\
16,50\end{array}$ & $\begin{array}{l}6,77 \\
6,86 \\
6,95\end{array}$ & $\begin{array}{l}11,25 \\
11,37 \\
11,49\end{array}$ \\
\hline
\end{tabular}




\begin{tabular}{|c|c|c|c|c|c|c|}
\hline \multirow{2}{*}{$\begin{array}{l}\text { Tamantho amostral } \\
\text { (por subparcela) }\end{array}$} & & \multicolumn{4}{|c|}{ Caso I } & \multirow{2}{*}{$\begin{array}{c}\text { Caso II } \\
\text { (o cará } \\
\text { ter })^{-}\end{array}$} \\
\hline & & $\begin{array}{l}\text { Híbridos } \\
\text { Simples }\end{array}$ & $\begin{array}{l}\text { Híbridos } \\
\text { Duplos }\end{array}$ & $\begin{array}{l}\text { Varie } \\
\text { dades }\end{array}$ & $\begin{array}{l}\text { Compos - } \\
\text { tos }\end{array}$ & \\
\hline 50 & $\begin{array}{c}\text { L.I. } \\
P \\
L . S .\end{array}$ & $\begin{array}{l}11,63 \\
11,78 \\
11,93\end{array}$ & $\begin{array}{l}10,23 \\
10,36 \\
10,49\end{array}$ & $\begin{array}{l}16,04 \\
16,24 \\
16,44\end{array}$ & $\begin{array}{l}6,65 \\
6,75 \\
6,85\end{array}$ & $\begin{array}{l}11,15 \\
11,28 \\
11,41\end{array}$ \\
\hline 55 & $\begin{array}{c}\text { L.I. } \\
\text { L.S. }\end{array}$ & $\begin{array}{l}11,56 \\
11,71 \\
11,86\end{array}$ & $\begin{array}{l}10,15 \\
10,28 \\
10,71\end{array}$ & $\begin{array}{l}15,99 \\
16,19 \\
16,39\end{array}$ & $\begin{array}{l}6,56 \\
6,66 \\
6,76\end{array}$ & $\begin{array}{l}11,08 \\
11,21 \\
11,34\end{array}$ \\
\hline 60 & $\begin{array}{c}\text { L.I. } \\
9 \\
L . S .\end{array}$ & $\begin{array}{l}11,51 \\
11,66 \\
11,81\end{array}$ & $\begin{array}{l}10,07 \\
10,21 \\
10,35\end{array}$ & $\begin{array}{l}15,94 \\
16,14 \\
16,34\end{array}$ & $\begin{array}{l}6,48 \\
6,58 \\
6,68\end{array}$ & $\begin{array}{l}11,02 \\
11,15 \\
11,28\end{array}$ \\
\hline
\end{tabular}

5.2.5 * Representação gräfica das equações de regressão

A partir dos valores da Tabela 29, foram construídos os gräficos das equações de regressão $(5.2 .3)$, os quais são apresen tados nas seguintes Figuras: híbridos simples (Figura 6), híbridos duplos (Figura 7), variedades (Figura 8), compostos (Figura 9) e o carāter (Figura 10). 
54.

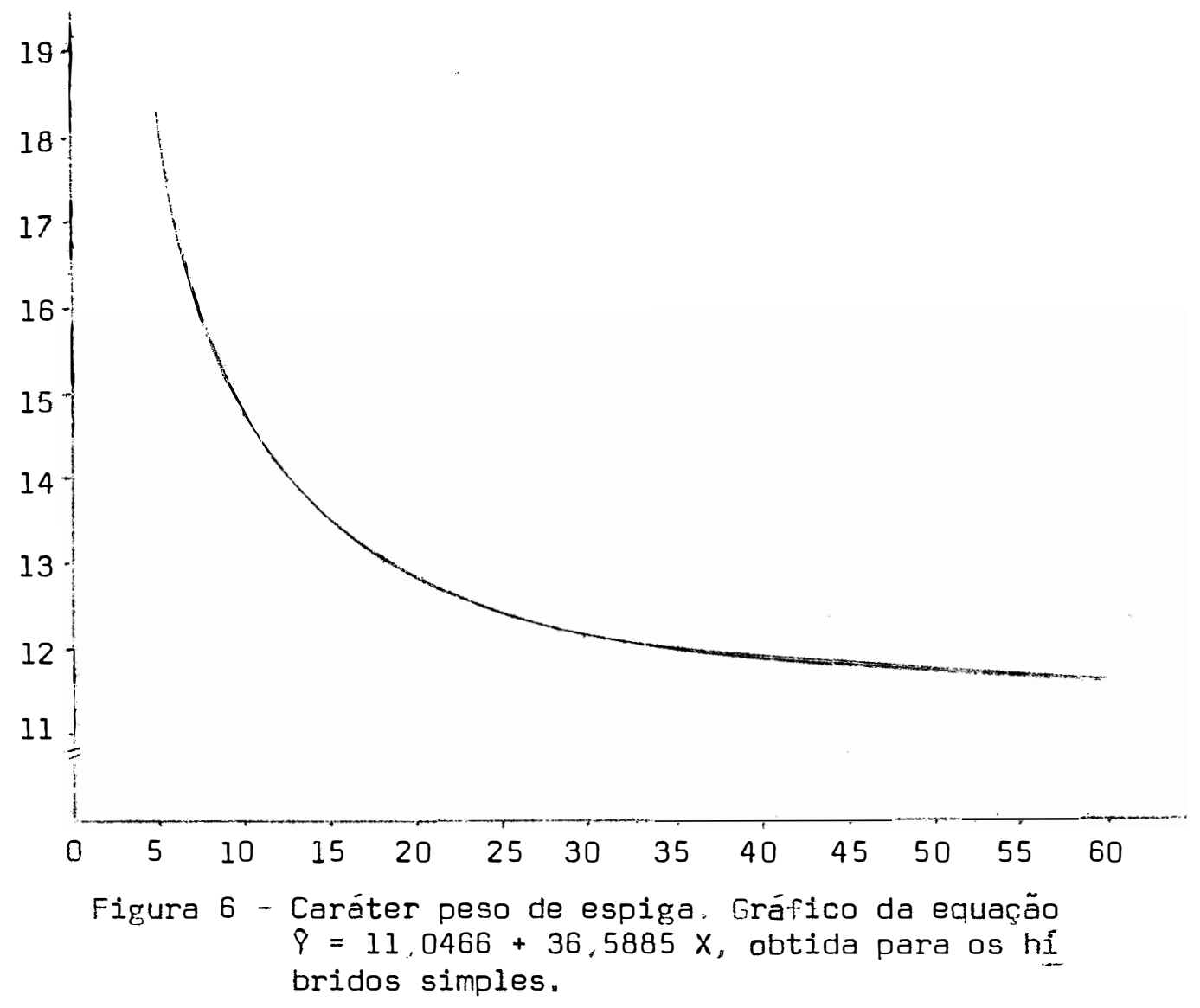


55.

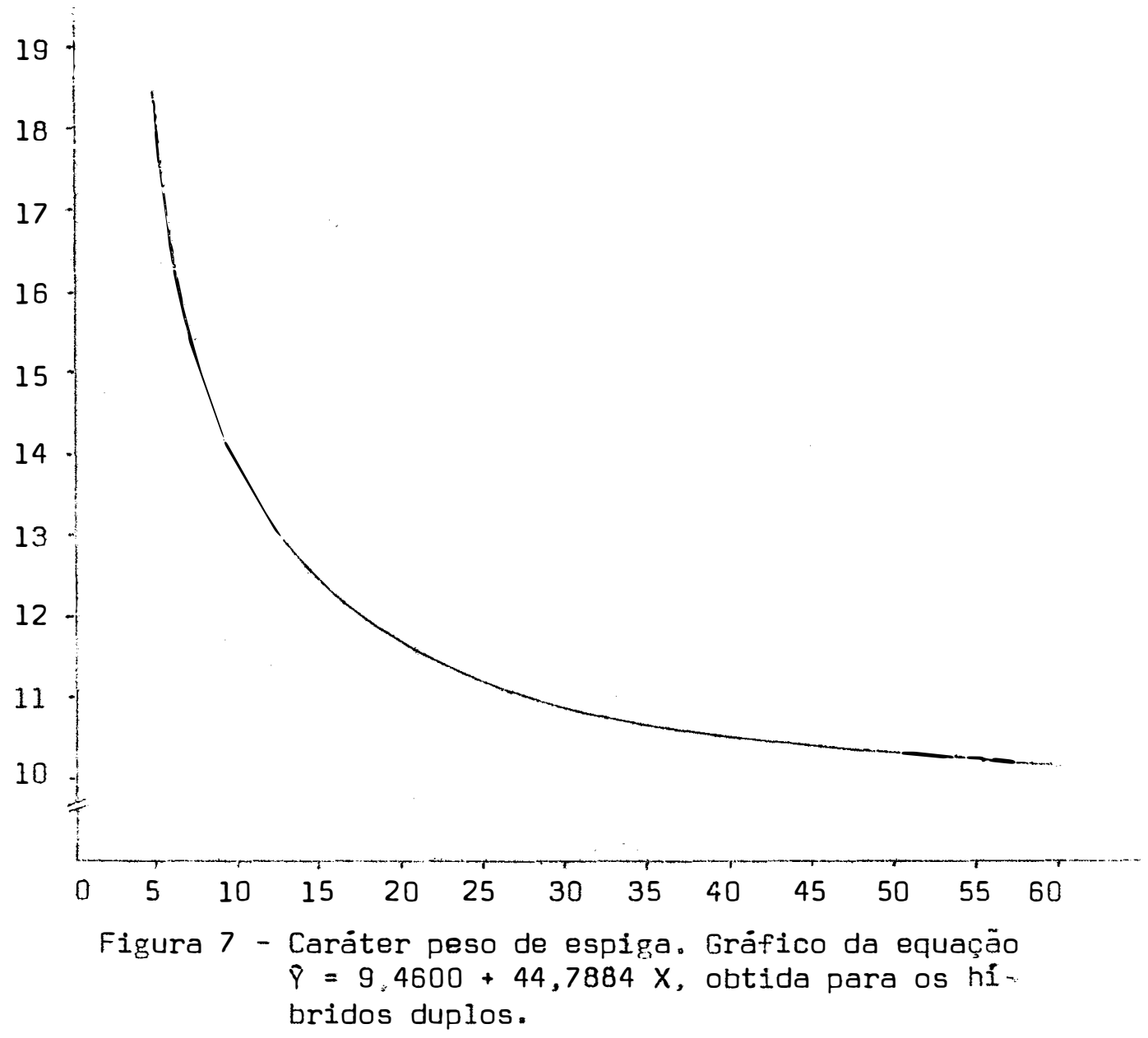


56.

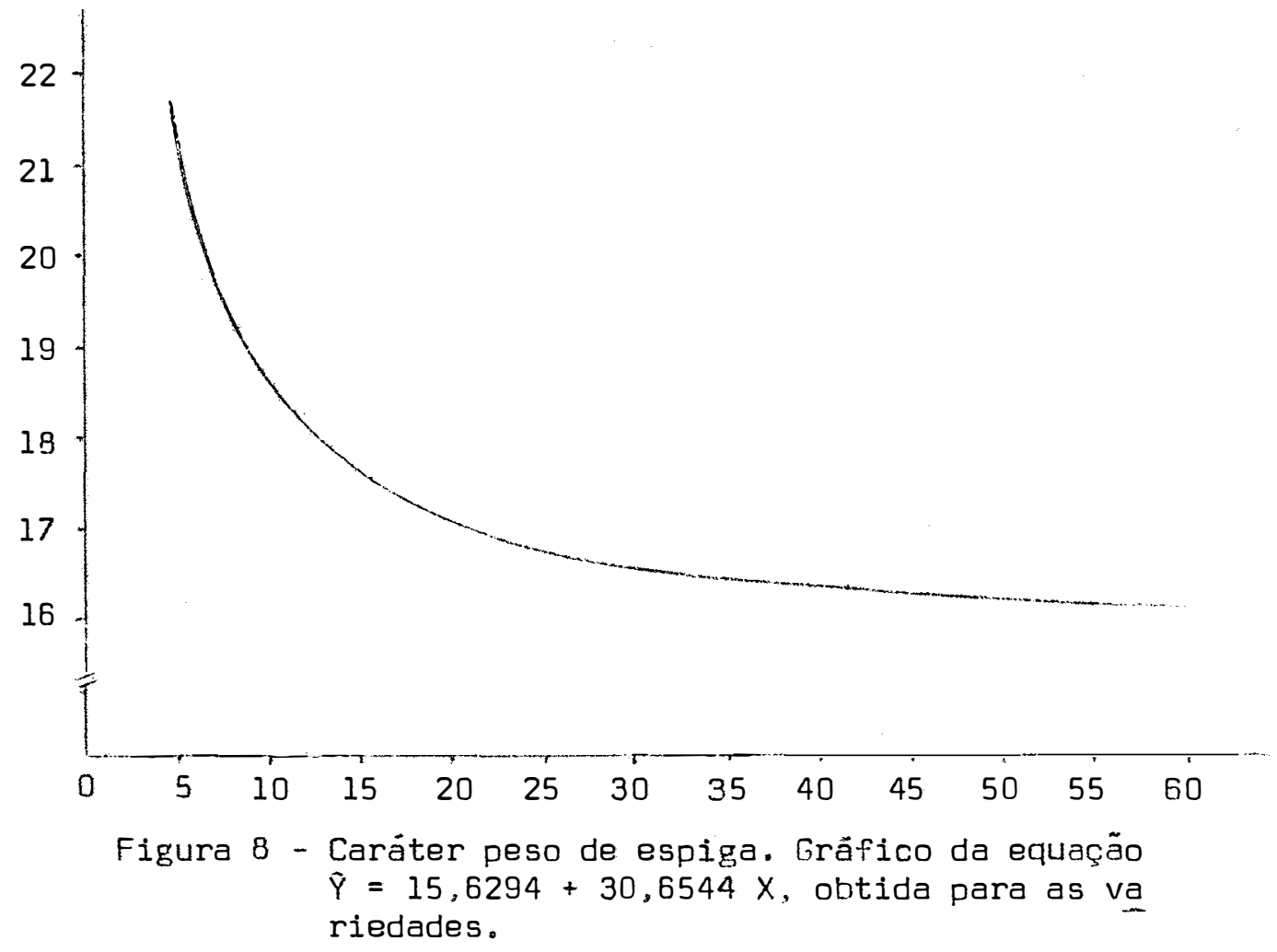




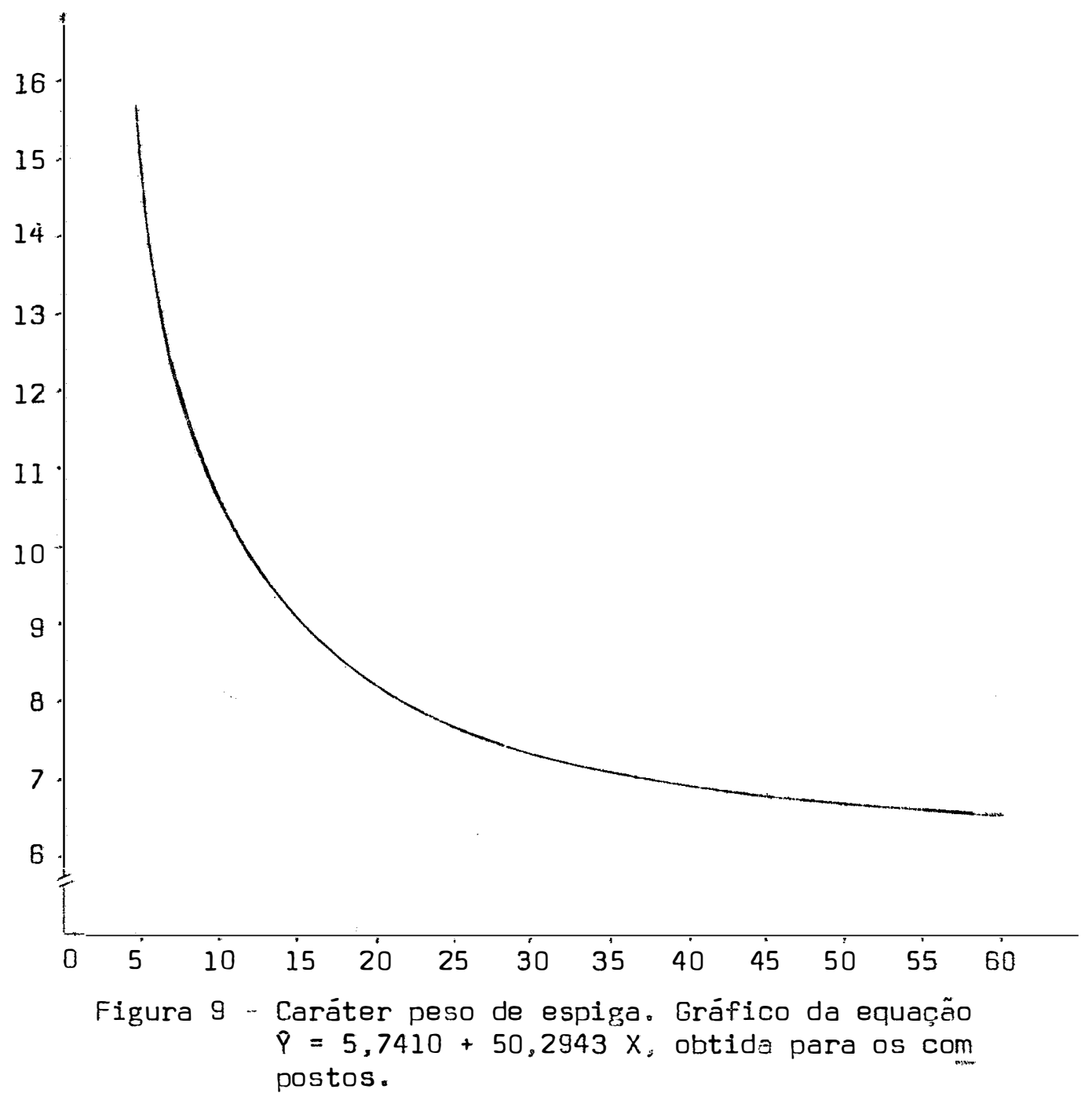


58.

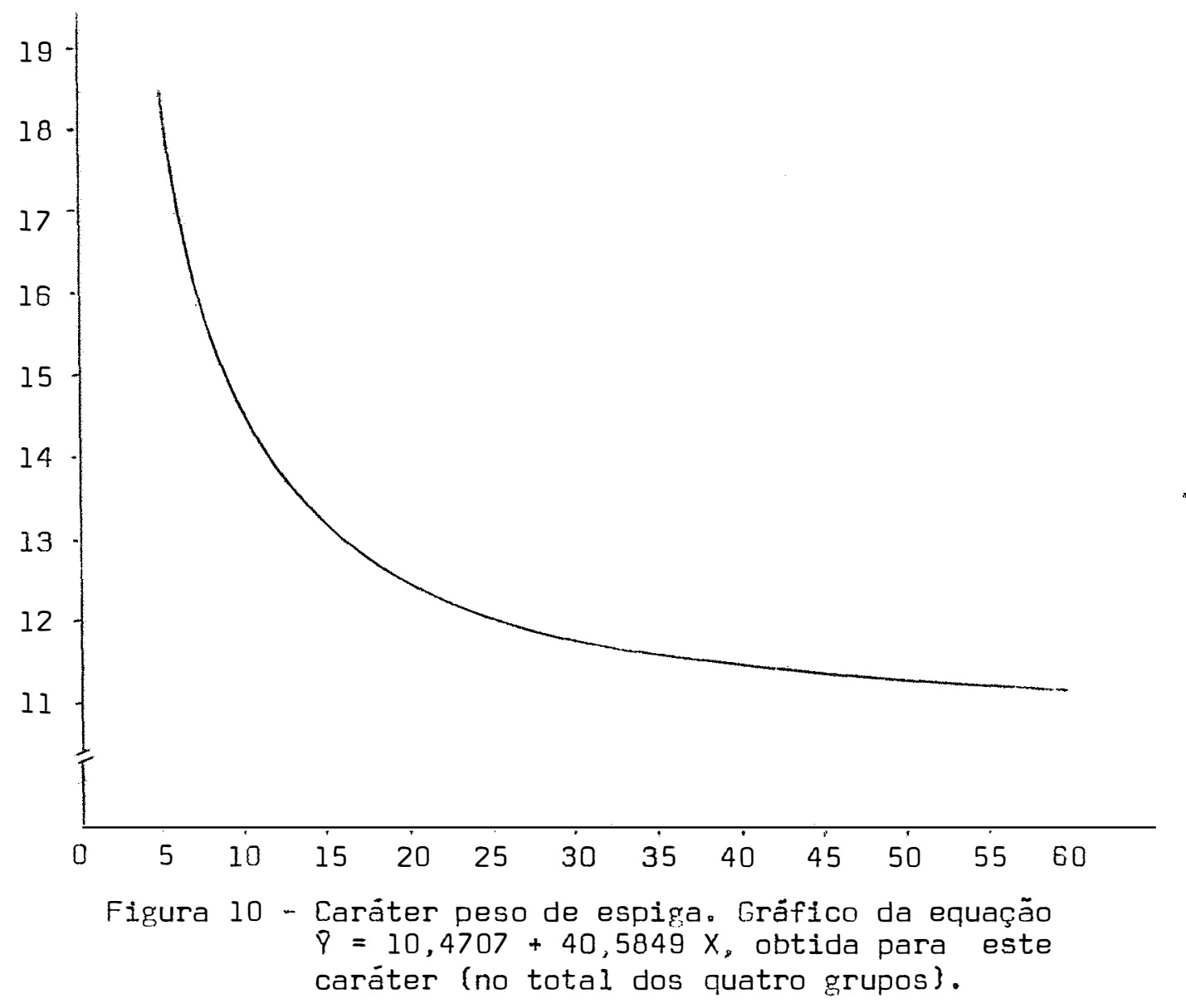


59.

\section{3 - Caráter Al tura da Planta}

\subsection{1 - Anälise de variância dos dados simulados}

Seguindo-se o mesmo procedimento de 5.1.1, apresen-

tam-se nas Tabelas de 30 a 33 os valores médios do quadrado médio do resíduo (b), média do grupo e coeficiente de variação a nível de planta, obtidos para os híbridos simples, híbridos duplos, varie dades e compostos, respectivamente.

Na Tabela 34 encontram-se os valores médios das médias das cultivares, relativos a 100 análises de variância, para todos os tamanhos amostrais.

Tabela 30 - Caréter altura da planta $(\mathrm{cm})$. Valores médios do quadra do médio do resíduo (b), média do grupo e coeficiente de variação, a nível de planta, obtidos de 100 análises de variância, para os híbridos simples.

\begin{tabular}{cccc}
\hline \multirow{2}{*}{$\begin{array}{c}\text { Tamanho amostral } \\
\text { (por subparcela) }\end{array}$} & \multicolumn{3}{c}{ Valor médio } \\
\cline { 2 - 4 } & QMR (b) & $\hat{\mathrm{m}}$ & C.V. (\%) \\
\hline 5 & $2.112,1103$ & 274,9460 & 7,39 \\
10 & $3.697,4160$ & 274,8948 & 6,89 \\
15 & $5.265,9610$ & 274,5333 & 6,75 \\
20 & $6.723,3497$ & 274,6559 & 6,59 \\
25 & $8.002,2228$ & 275,0170 & 6,41 \\
30 & $9.602,9902$ & 275,3378 & 6,43 \\
35 & $11.691,5212$ & 274,1823 & 6,54 \\
40 & $12.525,5100$ & 274,9496 & 6,37 \\
45 & $15.144,0291$ & 274,3175 & 6,60 \\
50 & $15.552,3434$ & 275,4974 & 6,33 \\
55 & $17.011,0356$ & 274,8618 & 6,32 \\
60 & $20.314,8897$ & 274,8582 & 6,61 \\
\hline
\end{tabular}


60.

Tabela 31 - Caräter altura da planta $(\mathrm{cm})$. Valores médios do quadra do médio do residuo (b), média do grupo e coeficiente de variação,a nível de planta, obtidos de 100 análises de variância, para os híbridos duplos.

\begin{tabular}{cccc}
\hline $\begin{array}{c}\text { Tamanho amostral } \\
\text { (por subparcela) }\end{array}$ & \multicolumn{3}{c}{ Valor médio } \\
\cline { 2 - 4 } & QMR (b) & $\hat{\mathrm{m}}$ & C.V.(\%) \\
\hline 5 & $1.120,9927$ & 296,9670 & 4,99 \\
10 & $1.815,5847$ & 296,9801 & 4,47 \\
15 & $2.613,9843$ & 297,0546 & 4,39 \\
20 & $3.276,2249$ & 297,3616 & 4,25 \\
25 & $4.066,3332$ & 297,2964 & 4,22 \\
30 & $4.962,0637$ & 297,2013 & 4,28 \\
35 & $5.751,9745$ & 297,2600 & 4,26 \\
40 & $6.415,9225$ & 297,0671 & 4,22 \\
45 & $7.695,3137$ & 297,3445 & 4,33 \\
50 & $7.568,8028$ & 297,3811 & 4,08 \\
55 & $8.503,0601$ & 296,8906 & 4,13 \\
60 & $9.537,7495$ & 297,2147 & 4,19 \\
\hline
\end{tabular}

Tabela 32 - Caráter altura da planta $(\mathrm{cm})$. Valores médios do quadra do médio do resíduo (b), média do grupo e coeficiente de variação, a nível de planta, obtidos de 100 análises de variância, para as variedades.

\begin{tabular}{cccc}
\hline \multirow{2}{*}{$\begin{array}{c}\text { Tamanho amostral } \\
\text { (por subparcela) }\end{array}$} & \multicolumn{3}{c}{ Valor médio } \\
\cline { 2 - 4 } & QMR (b) & $\tilde{\mathrm{m}}$ & C.V. (\%) \\
\hline 5 & 895,7537 & 324,8283 & 4,06 \\
10 & $1.291,0041$ & 324,5854 & 3,47 \\
15 & $1.665,1789$ & 325,1135 & 3,20 \\
20 & $2.082,8323$ & 324,9589 & 3,11 \\
25 & $2.505,5183$ & 324,7608 & 3,05 \\
30 & $2.709,9316$ & 325,7828 & 2,89 \\
35 & $3.367,7465$ & 324,7872 & 2,99 \\
40 & $3.603,0186$ & 325,1274 & 2,89 \\
45 & $3.836,3001$ & 325,1950 & 2,81 \\
50 & $4.421,4365$ & 324,9429 & 2,86 \\
55 & $4.550,7026$ & 325,1056 & 2,78 \\
60 & $5.051,3674$ & 324,8365 & 2,79 \\
\hline
\end{tabular}


Tabela 33 - Caráter altura da planta $(\mathrm{cm})$. Valores médios do quadra do médio do residuo(b), média do grupo e coeficiente dë variação, a nível de planta, obtidos de 100 análises de variância, para os compostos.

\begin{tabular}{cccc}
\hline \multirow{2}{*}{$\begin{array}{c}\text { Tamanho amostral } \\
\text { (por subparcela) }\end{array}$} & QMR (b) & $\hat{m}$ & Valor médio \\
\cline { 2 - 4 } & 774,7729 & 312,0953 & 3,93 \\
\hline 5 & $1.047,7721$ & 312,0840 & 3,23 \\
10 & $1.160,0210$ & $3.12,3060$ & 2,78 \\
15 & $1.468,5573$ & 311,7918 & 2,71 \\
20 & $1.621,1120$ & 312,0147 & 2,55 \\
25 & $1.838,5489$ & 311,8493 & 2,48 \\
30 & $1.957,5512$ & 312,0309 & 2,37 \\
35 & $2.221,0548$ & 312,1857 & 2,36 \\
40 & $2.301,7828$ & 311,6533 & 2,26 \\
45 & $2.608,5282$ & 311,6750 & 2,29 \\
50 & $2.975,9396$ & 312,0580 & 2,33 \\
55 & $2.877,7498$ & 312,0042 & 2,20 \\
60 & & & \\
\hline
\end{tabular}

Tabela 34 - Caräter altura da planta. Valores médios das médias das cultivares $(\mathrm{cm})$, relativos a 100 anälises de variância.

\begin{tabular}{cccccccccc}
\hline $\begin{array}{c}\text { Tamanho } \\
\text { amostral } \\
\text { (por sub }\end{array}$ parcela) & $\hat{m}_{1}$ & & $\hat{m}_{2}$ & $\hat{m}_{3}$ & $\hat{m}_{4}$ & $\hat{m}_{5}$ & $\hat{m}_{6}$ & $\hat{m}_{7}$ & $\hat{m}_{8}$ \\
\hline 5 & 273,6549 & 276,2370 & 299,1318 & 294,8021 & 324,7828 & 324,8737 & 318,6047 & 305,5860 \\
10 & 273,4511 & 276,3386 & 299,2971 & 294,6632 & 324,2492 & 324,9217 & 318,2469 & 305,9213 \\
15 & 273,7282 & 275,3384 & 299,5027 & 294,6066 & 324,8363 & 325,3907 & 318,6139 & 305,9985 \\
20 & 274,0962 & 275,2156 & 299,8077 & 294,9156 & 324,3452 & 325,5726 & 318,1013 & 305,4824 \\
25 & 274,5359 & 275,4981 & 299,8766 & 294,7164 & 324,8627 & 324,6590 & 318,3468 & 305,6527 \\
30 & 274,2044 & 276,4713 & 300,3704 & 294,0323 & 324,8756 & 326,6901 & 318,3136 & 305,3852 \\
35 & 272,5914 & 275,7733 & 300,1828 & 294,3373 & 324,3094 & 325,2652 & 318,4052 & 305,6567 \\
40 & 274,2539 & 275,6454 & 299,7624 & 294,3719 & 324,9267 & 325,3282 & 318,5638 & 305,8077 \\
45 & 273,1800 & 275,4552 & 300,1443 & 294,5450 & 324,7111 & 325,6791 & 318,1114 & 305,1955 \\
50 & 274,7272 & 276,2677 & 299,9296 & 294,8328 & 324,9397 & 324,9462 & 318,1170 & 305,2331 \\
55 & 273,9519 & 275,7719 & 299,5259 & 294,2556 & 324,8842 & 325,3272 & 318,3698 & 305,7424 \\
60 & 273,9783 & 275,7383 & 299,7033 & 294,7263 & 324,8587 & 324,8147 & 318,3555 & 305,6532
\end{tabular}

onde: 1 e 2 são híbridos simples; 3 e 4 híbridos duplos; 5 e 6 variedades; 7 e 8 compostos, apresentadas na mesma sequência de 4.1.1. 


\subsection{2 - Anălise de variância dos coeficientes de variação} e coeficiente de determinação

As anälises de variância dos coeficientes de variação, considerando-se a regressão, e os coeficientes de determinação encontram-se nas seguintes Tabelas: Caso I (Tabelas de 35 a 38) e Caso II (Tabela 39).

Tabela 35 - Caráter altura da planta. Anälise de variância dos coeficientes de variação, considerando-se a regressão, e coeficiente de determinação apresentados pelos híbridos simples.

\begin{tabular}{|c|c|c|c|c|}
\hline Causas de Variação & G.L. & S.Q. & Q.M. & $\mathrm{F}$ \\
\hline Regressão Linear & 1 & 88,0789 & 88,0789 & $75,14 \% \%$ \\
\hline Desvios da Regressão & 10 & 12,2836 & 1,2284 & 1,05 \\
\hline \multicolumn{5}{|c|}{ - } \\
\hline (Tratamentos) & $(11)$ & $(100,3625)$ & & \\
\hline Residuo & 1.188 & $1.392,5808$ & 1,1722 & \\
\hline Total & 1.199 & $1.492,9433$ & & \\
\hline
\end{tabular}


Tabela 36 - Caráter altura da planta. Análise de variância dos coeficientes de variação, considerando-se a regressão, e coeficiente de determinação apresentados pelos híbridos duplos.

\begin{tabular}{|c|c|c|c|c|}
\hline Causas de Variação & G.L. & $S \cdot Q$. & Q.M. & $\mathrm{F}$ \\
\hline Regressão Linear & 1 & 57,1020 & 57,1020 & $115,24 * *$ \\
\hline Desvios da Regressão & 10 & 4,6005 & 0,4601 & 0,93 \\
\hline (Tratamentos) & (11) & $(61,7025)$ & & \\
\hline Resíduo & 1.188 & 588,6431 & 0,4955 & \\
\hline Total & 1.199 & 650,3456 & & \\
\hline
\end{tabular}

Tabela 37 - Caráter altura da planta. Análise de variância dos coem ficientes de variação, considerando-se a regressão, e coeficiente de determinação apresentados pelas variedades.

\begin{tabular}{lcccc}
\hline Causas de Variação & G.L. & S.Q. & Q.M. & F \\
\hline Regressão Linear & 1 & 147,4498 & 147,4498 & $692,90 \%$ \&: \\
Desvios da Regressão & 10 & 2,9602 & 0,2960 & 1,39 \\
(Tratamentos) & $(11)$ & $(150,4100)$ & & \\
Resíduo & 1.188 & 252,7635 & 0,2128 & \\
\hline Total & 1.199 & 403,1735 & & \\
\hline
\end{tabular}

** = significativo ao nível de $1 \%$ de probabilidade;

$r^{2}=0,9803: \bar{r}^{2}=0,9783$. 
Tabela 38 - Caráter altura da planta. Análise de variãncia dos coeficientes de varı́ação, considerando-se a regressão, e coeficiente de determinação apresentados pelos compos-. tos.

\begin{tabular}{lccrrr}
\hline Causas de Variação & G.L. & S.Q. & Q.M. & F \\
\hline Regressão Linear & 1 & 271,1911 & 271,1911 & $1.364,14 \% *$ \\
Desvios da Regressão & 10 & 6,3381 & 0,6338 & $3,19 * *$ \\
(Tratamentos) & $(11)$ & $(277,5292)$ & & \\
Residuo & 1.188 & 236,2201 & 0,1988 & \\
\hline Total & 1.199 & 513,7493 & & \\
\hline
\end{tabular}

$* *$ = significativo ao nível de $1 \%$ de probabilidade; $r^{2}=0,9772 ; \bar{r}^{2}=0,9749$.

Tabela 39 - Caräter altura da planta. Anälise de variància dos coeficientes de variação, considerando-se a regressão, e coeficiente de determinação apresentados por este caráter (Caso II).

\begin{tabular}{lccrr}
\hline Causas de Variação & G.L. & S.Q. & Q.M. & $F$ \\
\hline Regressão Linear & 1 & 517,4266 & 517,4266 & $177,32 \% *$ \\
Desvios da Regressão & 10 & 5,8901 & 0,5890 & $0,20 \% *$ \\
& $(11)$ & $(523,3167)$ & \\
(Tratamentos) & 4.788 & $13.971,7382$ & 2,9181 \\
Residuo & 4.799 & $14.495,0549$ & & \\
\hline Total & & &
\end{tabular}




\section{3 .3 - Equações de regressão}

As equações de regressão, obtidas para o caráter altura da planta, foram:

$$
\text { (a) } \quad P=6,3245+5,3740 x \text {, }
$$

para os híbridos simples:

$$
\text { (b) } \quad P=4,0937+4,3270 x \text {, }
$$

para os híbridos duplos:

$$
\text { (c) } \quad P=2,7153+6,5932 x \text {, }
$$

para as variedades:

$$
\text { (d) } \quad P=2,1364+9,4298 x \text {, }
$$

para os compostos:

$$
\text { (e) } \quad P=3,8190+6,5127 x \text {. }
$$

para este caräter (Caso II).

5.3 .4 - Estimativas do coeficiente de variação e respectivos intervalos de confiança

As estimativas do coeficiente de variação, obtidas pelas equações de regressão (5.3.3), e seus respectivos intervalos de confiança são apresentadas na Tabela 40, para os Casos I e II. 
66.

Tabela 40 - Caráter altura da planta. Estimativas do coeficiente de variação $(\%)$ e respectivos iritervalos de confiança, ao nível de $5 \%$ de probabilidade, e $t=2$, obtidos para os Casos I e II.

\begin{tabular}{|c|c|c|c|c|c|c|}
\hline \multirow{2}{*}{$\begin{array}{l}\text { Tamanho amostral } \\
\text { (por subparcela) }\end{array}$} & & \multicolumn{4}{|c|}{ Caso I } & \multirow{2}{*}{$\begin{array}{c}\text { Caso II } \\
\text { (0 cará } \\
\text { ter })^{-}\end{array}$} \\
\hline & & $\begin{array}{l}\text { Híbridos } \\
\text { Simples }\end{array}$ & $\begin{array}{l}\text { Híbridos } \\
\text { Duplos }\end{array}$ & $\begin{array}{l}\text { Varie } \\
\text { dades }\end{array}$ & $\begin{array}{l}\text { Compos- } \\
\text { tos }\end{array}$ & \\
\hline 5 & $\begin{array}{l}L . I . \\
\text { L.S. }\end{array}$ & $\begin{array}{l}7,21 \\
7,40 \\
7,59\end{array}$ & $\begin{array}{l}4,83 \\
4,96 \\
5,09\end{array}$ & $\begin{array}{l}4,03 \\
4,11 \\
4,19\end{array}$ & $\begin{array}{l}3,94 \\
4,02 \\
4,10\end{array}$ & $\begin{array}{l}4,97 \\
5,12 \\
5,27\end{array}$ \\
\hline 10 & $\begin{array}{l}L_{. I} . \\
L . S .\end{array}$ & $\begin{array}{l}6,77 \\
6,86 \\
6,95\end{array}$ & $\begin{array}{l}4,47 \\
4,53 \\
4,59\end{array}$ & $\begin{array}{l}3,37 \\
3,41 \\
3,45\end{array}$ & $\begin{array}{l}3,04 \\
3,08 \\
3,12\end{array}$ & $\begin{array}{l}4,40 \\
4,47 \\
4,54\end{array}$ \\
\hline 15 & $\begin{array}{c}L_{0} I . \\
P \\
\text { L.S. }\end{array}$ & $\begin{array}{l}6,62 \\
6,68 \\
6,74\end{array}$ & $\begin{array}{l}4,34 \\
4,38 \\
4,42\end{array}$ & $\begin{array}{l}3,15 \\
3,18 \\
3,21\end{array}$ & $\begin{array}{l}2,74 \\
2,77 \\
2,80\end{array}$ & $\begin{array}{l}4,20 \\
4,25 \\
4,30\end{array}$ \\
\hline 20 & $\begin{array}{l}\text { L.I. } \\
P \\
L . S .\end{array}$ & $\begin{array}{l}6,53 \\
6,59 \\
6,65\end{array}$ & $\begin{array}{l}4,27 \\
4,31 \\
4,35\end{array}$ & $\begin{array}{l}3,03 \\
3,06 \\
3,09\end{array}$ & $\begin{array}{l}2,58 \\
2,61 \\
2,64\end{array}$ & $\begin{array}{l}4,09 \\
4,14 \\
4,19\end{array}$ \\
\hline 25 & $\begin{array}{l}L_{0} I . \\
\text { L.S. }\end{array}$ & $\begin{array}{l}6,48 \\
6,54 \\
6,60\end{array}$ & $\begin{array}{l}4,23 \\
4,27 \\
4,31\end{array}$ & $\begin{array}{l}2,96 \\
2,99 \\
3,02\end{array}$ & $\begin{array}{l}2,48 \\
2,51 \\
2,54\end{array}$ & $\begin{array}{l}4,03 \\
4,08 \\
4,13\end{array}$ \\
\hline 30 & $\begin{array}{c}L_{0} I . \\
\text { L.S. }\end{array}$ & $\begin{array}{l}6,43 \\
6,50 \\
6,57\end{array}$ & $\begin{array}{l}4,20 \\
4,24 \\
4,28\end{array}$ & $\begin{array}{l}2,92 \\
2,95 \\
2,98\end{array}$ & $\begin{array}{l}2,42 \\
2,45 \\
2,48\end{array}$ & $\begin{array}{l}3,99 \\
4,04 \\
4,09\end{array}$ \\
\hline 35 & $\begin{array}{l}L_{0} I_{0} \\
\text { L.S. }\end{array}$ & $\begin{array}{l}6,41 \\
6,48 \\
6,55\end{array}$ & $\begin{array}{l}4,18 \\
4,22 \\
4,26\end{array}$ & $\begin{array}{l}2,88 \\
2,91 \\
2,94\end{array}$ & $\begin{array}{l}2,38 \\
2,41 \\
2,44\end{array}$ & $\begin{array}{l}3,96 \\
4,01 \\
4,06\end{array}$ \\
\hline 40 & $\begin{array}{c}\text { L.I. } \\
P \\
L . S .\end{array}$ & $\begin{array}{l}6,39 \\
6,46 \\
6,53\end{array}$ & $\begin{array}{l}4,15 \\
4,20 \\
4,25\end{array}$ & $\begin{array}{l}2,86 \\
2,89 \\
2,92\end{array}$ & $\begin{array}{l}2,34 \\
2,37 \\
2,40\end{array}$ & $\begin{array}{l}3,93 \\
3,98 \\
4,03\end{array}$ \\
\hline 45 & $\begin{array}{c}\text { L.I. } \\
P \\
L . S .\end{array}$ & $\begin{array}{l}6,37 \\
6,44 \\
6,51\end{array}$ & $\begin{array}{l}4,14 \\
4,19 \\
4,24\end{array}$ & $\begin{array}{l}2,84 \\
2,87 \\
2,90\end{array}$ & $\begin{array}{l}2,32 \\
2,35 \\
2,38\end{array}$ & $\begin{array}{l}3,91 \\
3,96 \\
4,01\end{array}$ \\
\hline
\end{tabular}


(continuação - Tabela 40)

\begin{tabular}{|c|c|c|c|c|c|c|}
\hline \multirow{2}{*}{$\begin{array}{l}\text { Tamanho amostral } \\
\text { (por subparcela) }\end{array}$} & & \multicolumn{4}{|c|}{ Caso I } & \multirow{2}{*}{$\begin{array}{c}\text { Caso II } \\
\text { (O cará } \\
\text { ter })^{-}\end{array}$} \\
\hline & & $\begin{array}{l}\text { Híbridos } \\
\text { Simples }\end{array}$ & $\begin{array}{l}\text { Híbridos } \\
\text { Duplos }\end{array}$ & Varie & $\begin{array}{l}\text { Compos- } \\
\text { tos }\end{array}$ & \\
\hline 50 & $\begin{array}{c}L_{0} I . \\
\varphi \\
L . S .\end{array}$ & $\begin{array}{l}6,36 \\
6,43 \\
6,50\end{array}$ & $\begin{array}{l}4,13 \\
4,18 \\
4,23\end{array}$ & $\begin{array}{l}2,82 \\
2,85 \\
2,88\end{array}$ & $\begin{array}{l}2,30 \\
2,33 \\
2,36\end{array}$ & $\begin{array}{l}3,89 \\
3,95 \\
4,01\end{array}$ \\
\hline 55 & $\begin{array}{c}L_{0} I . \\
P \\
L . S .\end{array}$ & $\begin{array}{l}6,35 \\
6,42 \\
6,49\end{array}$ & $\begin{array}{l}4,12 \\
4,17 \\
4,22\end{array}$ & $\begin{array}{l}2,81 \\
2,84 \\
2,87\end{array}$ & $\begin{array}{l}2,28 \\
2,31 \\
2,34\end{array}$ & $\begin{array}{l}3,88 \\
3,94 \\
4,00\end{array}$ \\
\hline 60 & $\begin{array}{l}L_{0} I . \\
\text { L.S. }\end{array}$ & $\begin{array}{l}6,33 \\
6,41 \\
6,49\end{array}$ & $\begin{array}{l}4,12 \\
4,17 \\
4,22\end{array}$ & $\begin{array}{l}2,80 \\
2,83 \\
2,86\end{array}$ & $\begin{array}{l}2,26 \\
2,29 \\
2,32\end{array}$ & $\begin{array}{l}3,87 \\
3,93 \\
3,99\end{array}$ \\
\hline
\end{tabular}

5.3.5 - Representação gräfica das equações de regressão

A partir dos valores da Tabela 40, foram construídos os gräficos das equações de regressão (5.3.3), os quais são apresen tados nas seguintes Figuras: híbridos simples (Figura 1i), híbridos duplos (Figura 12), variedades (Figura 13), compostos (Figura 14) e o caräter (Figura 15). 
68.

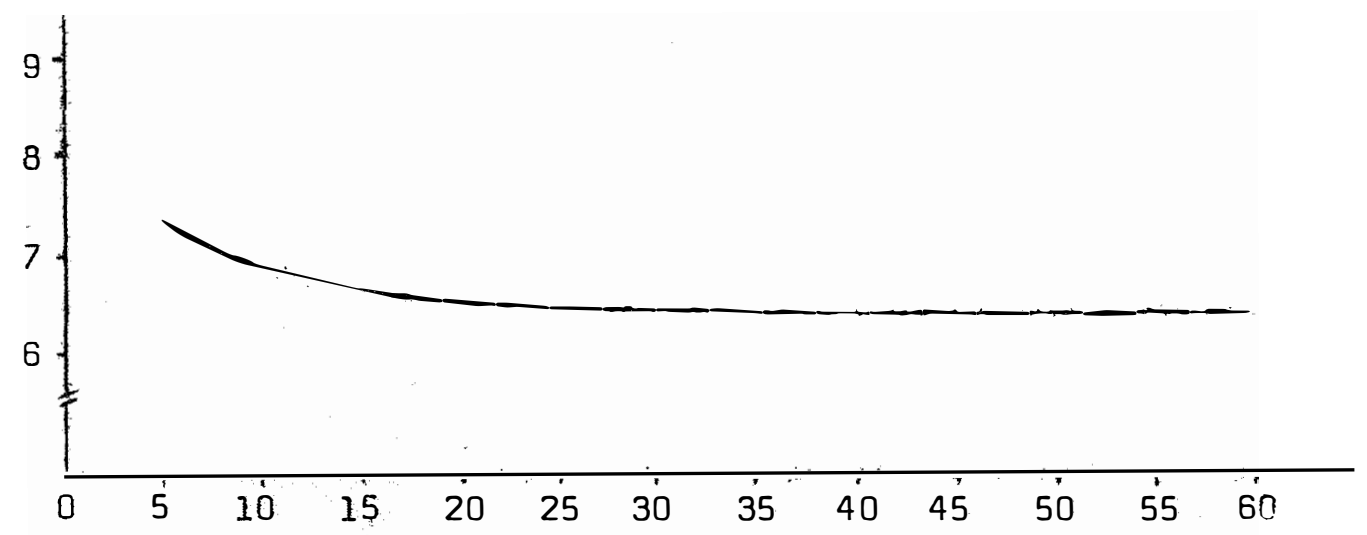

Figura 11 - Caráter altura da planta. Gráfico da equação $P=6,3245+5,3740 X$, obtida para os híbridos simples.

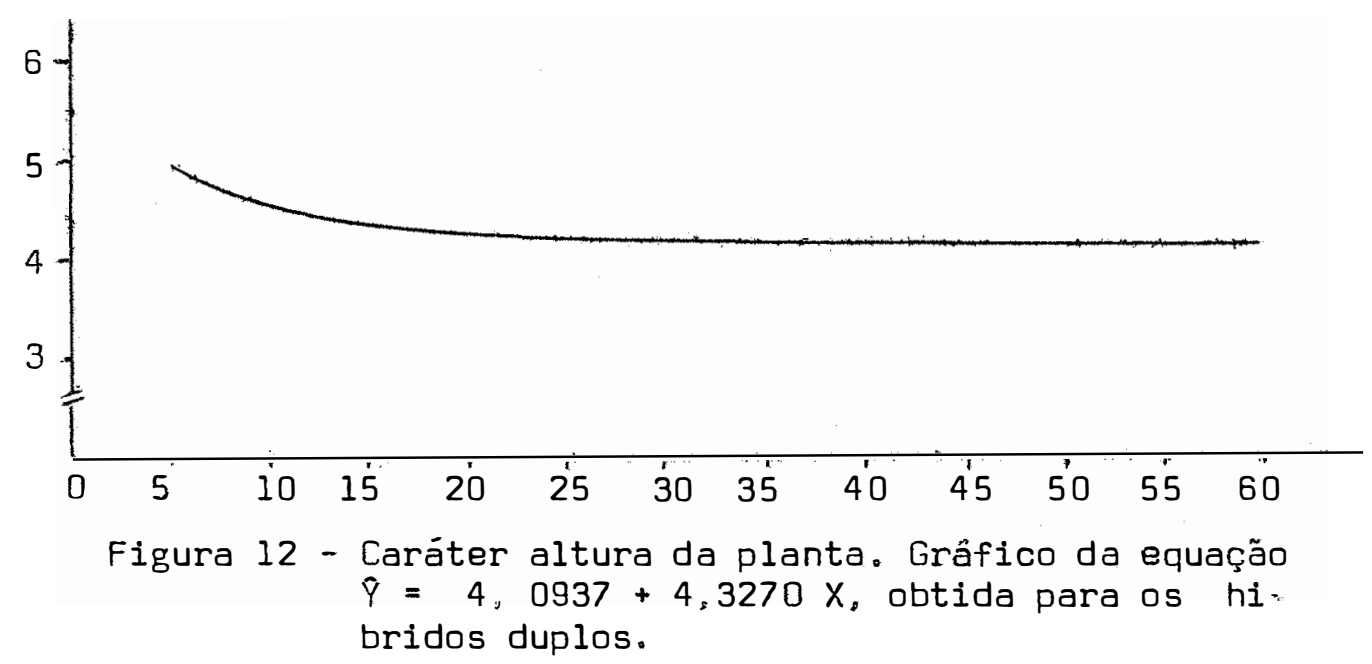




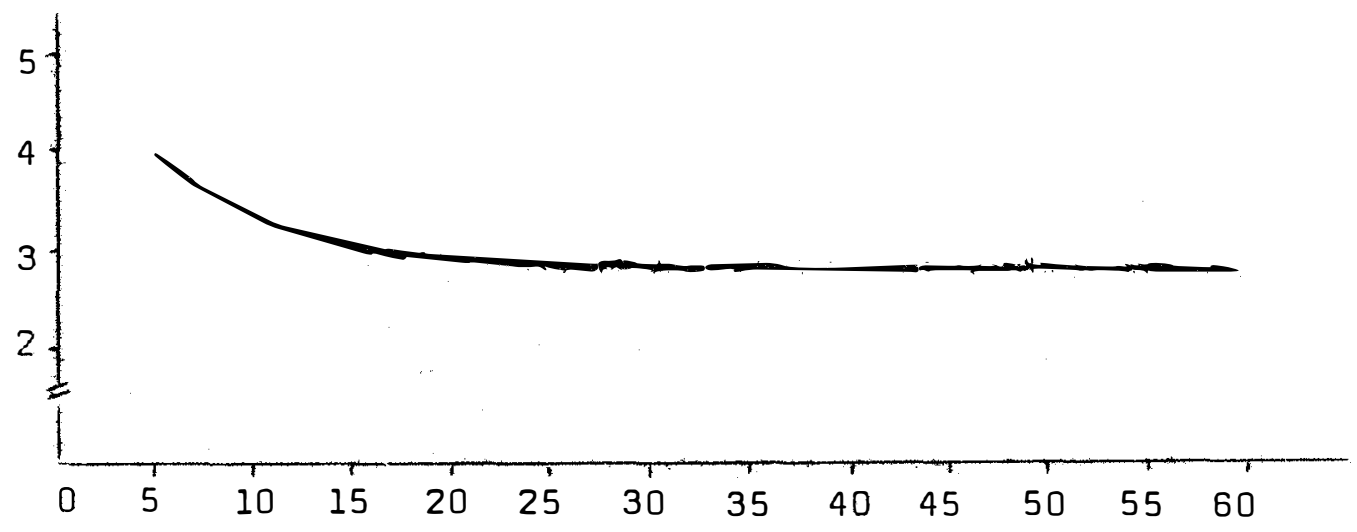

Figura 13 - Caráter altura da planta. Gräfico da equação $\hat{\gamma}=2,7153+6.5932 X$, obtida para as variedades.

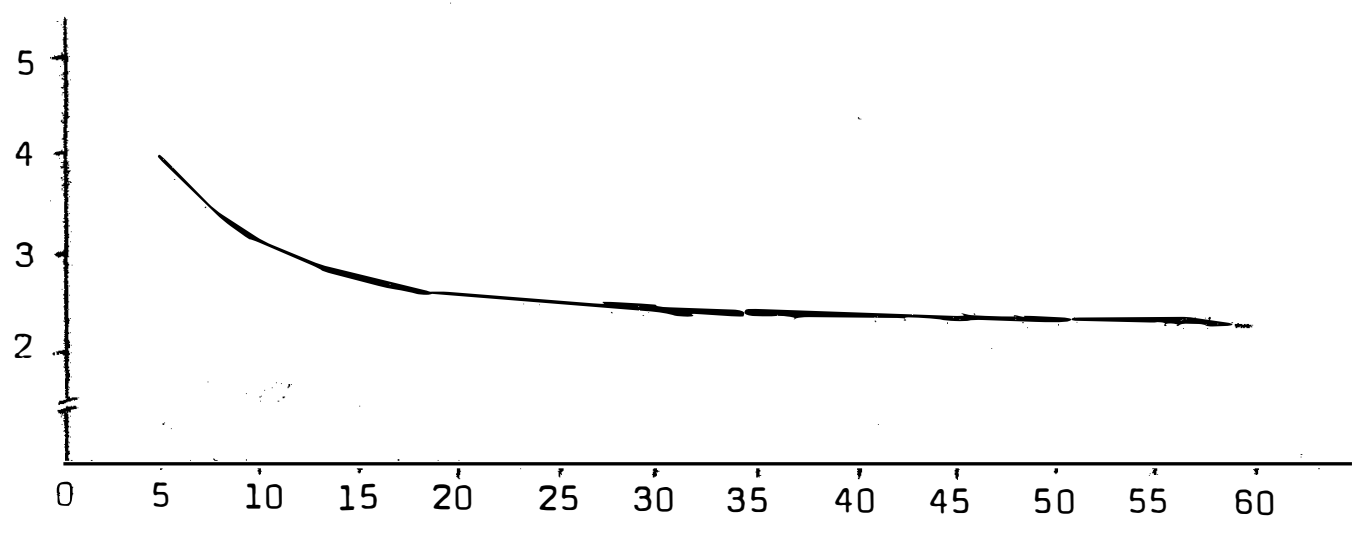

Figura 14 - Caráter altura da planta. Gráfico da equação $\hat{Y}=2,1364+9,4298 X$, obtida para os compos tos. 
70.

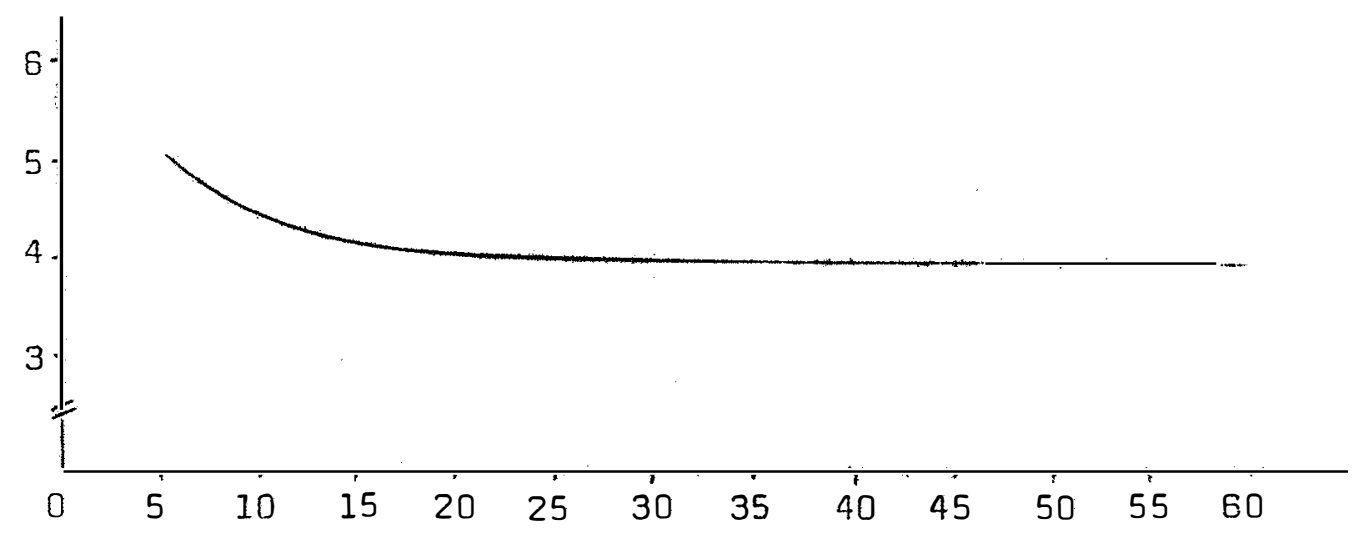

Figura 15 - Caräter altura da planta. Gräfico da equação $\hat{Y}=3,8190+6,5127 X$, obtida para este cará ter (no total dos quatro grupos). 


\section{DISCUSSÃO}

Para os três caracteres, observou-se que, à medida que o tamanho amostral aumentou, o valor médio do quadrado médio do resíduo (b) também aumentou, em todos os grupos de cultivares. Entretanto, os aumentos näo foram proporcionais.

De uma maneira geral, para os três caracteres, os va lores médios das médias dos grupos de cultivares foram pouco afetados pelo tamanho amostral, principalmente para o caráter peso de 50 grãos.

Para todos os caracteres e grupos de cultivares, de um modo geral, o valor médio do coeficiente de variação decresceu com o aumento do tamanho amostral, sendo que o decréscimo foi mais acentuado ao passar de cinco para dez plantas por subparcela. Estes resultados concordam com as observações de LANA et alii (1953). 
O caräter peso de 50 gräos apresentou valores mëdios dos coeficientes de variação intermediários aos dos demais caracteres, para todos os grupos de cultivares e tamanhos amostrais. Os decréscimos, entre os valores médios dos coeficientes de variação dos extremos amostrais, foram também intermediários aos dos outros caracteres, para os quatro grupos de cultivares.

o caráter peso de espiga apresentou os mais altos va lores médios dos coeficientes de variação, para todos os grupos de cultivares e tamanhos amostrais. Com relação ao coeficiente de variação, foi o caráter mais sensível ao aumento do tamanho amostral. pois apresentou os maiores decréscimos, entre os valores médios dos coeficientes de variação dos extremos amostrais, para todos os grupos de cultivares.

0 caráter altura da planta apresentou os mais baixos valores médios dos coeficientes de variação, para todos os grupos de cultivares e tamanhos amostrais. Apresentou também os menores decréscimos, entre os valores médios dos coeficientes de variação dos extremos amostrais, para todos os grupos de cultivares.

Os valores médios das médias das cultivares, de um mo do geral, variaram pouco com o tamanho amostral, porém mantiveram a mesma ordem de grandeza em cada caráter, principalmente no caráter peso de 50 grãos. Isto faz crer que para estudos de competição de cultivares, com base em um destes caracteres, poderão ser tomadas pequenas amostras. 
Para os três caracteres, todos os valores do teste $F$ indicaram significância, ao nível de $1 \%$ de probabilidade, para a re gressão linear. Das quinze análises de variāncia, considerando-se a regressão, duas apresentaram valores de F significativos para os des vios da regressão e três altamente significativos. Entretanto, mesmo nessas análises de variáncia, a regressão linear foi altamente significativa em relação aos desvios da regressão. Para todos os ca racteres e grupos de cultivares, os valores dos coeficientes de determinação ajustados foram bem altos, sendo superiores a 0,97 em tre ze das quinze análises de variāncia. Sendo assim, de uma maneira ge ral, pode-se considerar satisfatório o ajustamento pela equação de regressão adotada.

Nos três caracteres, os maiores valores dos coeficientes de determinação ajustados foram apresentados pelos próprios caracteres (Caso II), seguidos pelo grupo das variedades.

Aplicando-se o método da curvatura máxima (Figuras de 1 a 4), observa-se que para o carāter peso de 50 grãos, o tamanho ótimo da amostra situou-se na faixa de 10 a 15 plantas por subparcela, para os quatro grupos de cultivares. Ainda por este método (Figur.a 5), pode-se considerar que o tamanho ótimo, para o caráter peso de 50 grãos, foi de 13 plantas por subparcela.

Pelo método da curvatura máxima (Figuras de 6 a 9), observa-se que, para o carâter peso de espiga, o tamanho ótimo situou-se na faixa de 12 a 17 plantas por subparcela, para os quatro 
grupos de cultivares. A aplicação do mesmo método (Figura 10), permite que se considere que, para o caráter peso de espiga, o tamanho ötimo foi de 15 plantas por subparcela.

O método da curvatura máxima (Figuras de 11 a 14)per mite observar-se que, para o caráter altura da planta, o tamanho ótimo situou-se próximo a 5 plantas por subparcela, para os quatro grupos de cultivares. 0 mesmo método (Figura 15), permite que se con sidere que, para o caráter altura da planta, o tamanho ótimo foi de 5 plantas por subparcela.

As consideraçōes dos três parāgrafos anteriores, per mitem observar-se que, para todos os caracteres estudados, o tamanho amostral praticamente não variou entre os grupos de cultivares. o tamanho amostral variou com o caráter estudado, tendo.a altura da planta, apresentado o menor valor. 
75.

\section{CONCLUSÕES}

Com base nos resultados obtidos, pode-se concluir que:

a) Em todos os caracteres estudados, o maior decréscirilo do coe ficiente de variação ocorreu quando o tamanho amostral passou de cin co para dez plantas por subparcela, para os quatro grupos de cultivares.

b) Para cada caráter, de um modo geral, os valores médios das médias das cultivares variaram pouco com o tamanho amostral, porém mantiveram a mesma ordem de grandeza.

c) Para o caráter peso de 50 grãos, baseando-se no método da curvatura máxima, o tamanho ótimo amostral foi de treze plantas por subparcela. 
76.

d) Para o caráter peso de espiga, baseando-se no método da cur vatura máxima, o tamanho ótimo amostral foi de quinze plantas por subparcela.

e) Para o caráter altura da planta, baseando-se no método da curvatura máxima, o tamanho ótimo amostral foi de cinco plantas por subparcela.

f) Dentro de cada caráter, o tamanho amostral praticamente não variou com os grupos de cultivares.

g) Dentro de cada grupo de cultivares, o tamanho amostral variou com os caracteres estudados. 


\section{SUMMARY}

The main purpose of this work wes to find out the optimum sample size for 50 kernels weight, ear weight and plant height in four groups of corn populations, namely: single crosses, double crosses, varieties and composites. Also, the optimum sample size for the groups as a whole was investigated.

To obtain estimates of the fixed effects and variance components, data were taken from two experiments conducted respectively in 1972/73 and 1973/74. The design was a split-plot with whole plots in randomized complete blocks. For each group, data of two cultivars were used.

These estimates based on experimental data were considered for simulation using the model:

$$
x_{i j k \ell}=m+t_{i}+b_{j}+(t b)_{i j}+t_{k}^{\prime}+\left(t t^{\prime}\right)_{i k}+e_{i j k}+n_{i j k l} .
$$


For each character and group, twelve sample sizes were chosen, namely: 5, 10, 15, 20, 25, 30, 35, 40, 45, 50, 55 and 60 plants per sub-plot, with one hundred replications for each sample size。

$$
\text { For each simulated experiment an estimate of the }
$$
coeficient of variation at a single plant basis was obtained. From these estimates the model $Y=A+B X+e$ was fitted, being $X$ the reciprocal of the sample size.

Generally, for each character, the cultivar averages did not vary considerably with sample size. The method of maximum curvature was used to find the optimum size. The results indicated that optimum sizes were: 13, 15 and 5 plant per sub-plot relative to 50 kernels weight, ear weight and plant height, respectively. There was no variation in optimum sample size among groups for each character. 


\section{LITERATURA CITADA}

BOX, G.E.P. e M.E. MULLER, 1958. A note on the generation of randon normal deviates. Annals Mathematical Statistics. Baltimore, 29; $610-611$.

D'AULISIO, M. de B.G., 1976. A variància dos pontos de máximo ou de mínimo de equações de regressão de segundo grau. Piracicaba, ESALQ/USP, 61 PP. (Dissertação de Mestrado).

FEDERER, W.T., 1955. Experimental Design. Nova York, The Macmillan Company. 544 pp 。

FERREIRA, C.A., 1976. A estimativa do volume de madeira aproveita vel para celulose, em povoamentos de Eucaliptus sp. Piracicaba, ESALQ/USP, 112 pP. (Dissertação de Mestrado).

FREY, K.J. e P. RODGERS, 1961. Yield components in oats. v. optimum number of replicates and samples per plot for spikelet counts. Agronomy Journal, Madison, 53:28-29. 
GODOI, C.R. de M., 1978. Sobre a simulação de variáveis binormais. Ciência e Cultura. São Paulo, 30(6):697-701.

HOFFMANN, R. e S。VIEIRA, 1977. Análise de Regressão: Uma Introdução à Econometria. São Paulo, HUCITEC, Editora da Universidade de São Paulo. 339 pp.

IMMER, F.R., 1932. A study of sampling technic with sugar beets. Journal Agricultural Research. Washington: 44(8):633-647.

KEMPTHORNE, 0。, 1965. The Design and Analysis of Experiments. 4a. edição. Nova York, John Wiley \& Sons, Inc. 631 pp.

KOCH, E。J。 e J.A. RIGNEY, 1951. A method of estimating optimum plot size from experimental data. Agronomy Journal。 Madison, 43:17-21。

LANA, E.P.: P.G. HOMEYER e E.S. HABER, 1953. Field plot technique in vegetable crops. Proceedings American Society Horticultural. Science. St. Joseph, 62:21-30.

LeROUX, E.J., 1961. Variation between samples of fruit and of fruit, damages mainly from insect pests, on apple in Quebec. Canadian, Entomologist. Ottawa, 93:680-694.

PIMENTEL GOMES, F。, 1976. Curso de Estatística Experimental. 6a. edição. São Paulo, Livraria Nobel. 430 pp.

SÁNCHEZ, F.M. = 1972. Tamaño de muestra para representar poblaciones de maiz. Agrociencia. Chapingo, Sërie $B(8): 163-177$. 